Article

\title{
Investigation the Influence of Different Salts on the Degradation of Organic Dyes Using Non-Thermal Plasma
}

\author{
Ahmed El-Tayeb ${ }^{1,2, *}$, Ahmed H. El-Shazly ${ }^{2}$ and Marwa F. Elkady ${ }^{2,3}$ \\ 1 Electric Engineering Department, Faculty of Energy Engineering, Aswan University, Aswan 81528, Egypt \\ 2 Chemical and Petrochemicals Engineering Department, Egypt-Japan University of Science and Technology, \\ New Borg El-Arab City, Alexandria 21934, Egypt; elshazly_a@yahoo.com (A.H.E.-S.); \\ marwa.elkady@ejust.edu.eg (M.F.E.) \\ 3 Fabrication Technology Department, Advanced Technology and New Materials Research Institute \\ (ATNMRI), City of Scientific Research and Technology Applications (SRTA City), Alexandria 21934, Egypt \\ * Correspondence: ahmed.khalil@ejust.edu.eg; Tel.: +20-10-9907-4051
}

Academic Editor: Rodolfo Araneo

Received: 28 July 2016; Accepted: 20 October 2016; Published: 26 October 2016

\begin{abstract}
In dye decolorization tests a non-thermal plasma (NTP) corona discharge generated by a high voltage pin-to-ground plate displayed $82 \%$ color removal within $11 \mathrm{~min}$. Total color removal was accomplished after $28 \mathrm{~min}$. Different salts such as $\mathrm{KCl}, \mathrm{NaCl}, \mathrm{CaCl}_{2}$ and $\mathrm{AlCl}_{3}$ were utilized to check the influence of conductivity changes on the dye decolorization process. Higher dye solution conductivity improved the color removal efficiency. The discharge energy and degradation efficiency were computed for diverse concentrations for $\mathrm{NaCl}, \mathrm{KCl}, \mathrm{CaCl}_{2}$ and $\mathrm{AlCl}_{3}$, whereby it was noticed that the salts generally have a small impact on the level of dye decolorization using corona discharge. In addition, the essential reactive species involved in the oxidation of organic dye compounds such as ozone $\left(\mathrm{O}_{3}\right)$ generated in treated water and hydrogen peroxide $\left(\mathrm{H}_{2} \mathrm{O}_{2}\right)$ were investigated and the energetic species that produced the non-thermal plasma at the optimum operation time were determined. Energy yields for decolorization and Electrical Energy per Order (EE/O) were calculated for different concentrations of $\mathrm{NaCl}, \mathrm{KCl}, \mathrm{CaCl}_{2}$ and $\mathrm{AlCl}_{3}$. This work may help in designing plasma systems appropriate for treatment of industrial wastewaters polluted by dyes.
\end{abstract}

Keywords: non-thermal plasma (NTP); wastewater treatment; corona discharge; dye decolorization; ozone generation; pin-to-plate

\section{Introduction}

Contamination in wastewaters created during manufacturing process is a very serious issue around the planet, and particularly in Egypt. In regular water treatment systems, wastewater might be filtered utilizing organic membranes or mixed treatment strategies can be used. In the old-style treatment methods waters, may be treated by either chemical or biological methods. These techniques often have some issues like the duration and cost of treatment, the requirement for big facilities, and the existence of some pollutants that are not easily degraded. Therefore, the implementation of advanced unconventional water-treatment tools that can resolve these difficulties is vital. The best solution is an ozone treatment system [1]. There are a variety of ways to generate non-thermal plasmas which include dielectric barrier discharge (DBD), RF, and corona discharge. Corona discharge is considered a problem in power transmission applications, due to the losses caused and the generation of radio interference in high voltage transmission lines and equipment, but on the other hand corona discharges in gases have found many practical applications, for example in plasma reactors, electrophotography, electrostatic separation, cold plasma chemistry, air pollution control, electrostatic printing, etc. In many 
of these applications multipoint discharge electrodes of different shapes and configurations are utilized. Dielectric barrier discharge (DBD) is the most common method used for non-thermal plasma generation. These discharges from the surface have a random origination and are composed of microdischarges in the gap. The prevention of sparks is a major advantage for DBD; however, there is also a risk of the dielectric material depositing onto the substrate being process or interacting with the sample and thus contaminating it. The addition of the dielectric material complicates the reactor design. The main benefit of capturing the charged species is a reduction in the chemical reactions on the surface. Another drawback the equipment is more expensive and adds additional layers of potential failure points to the system. Ozone can be created with an extensive variety of anode and release designs; the most prominent is $\mathrm{DBD}$. Corona discharges can generate $\mathrm{O}$ radicals (and thus ozone) with very great energy content. A corona discharge is a high voltage, DC or AC plasma source that creates micro-arcs using ambient air. The needed equipment is easily constructed and does not require vacuum or pump-down time. Most industrial corona discharge sustems consist of a thin wire or some other sharp point that is connected to a high voltage source (10 kV or higher). The voltage provided to the wire is higher than the breakdown electric field of the surrounding gas and thus produces an active coronal region of a certain radius, the electric field drops below the breakdown voltage of the gas and the corona ceases to exist with the exception of ions that may carry the current to surrounding walls or electrodes. Ultraviolet (UV) radiation is also present outside the active region of the corona discharge. Most corona DC discharges are generated from positive voltage due to beading instabilities associated with negative potentials, however alternating voltage (AC) leads to sequential waves of positive and negative ions. The disadvantages of corona discharges include the necessity for high voltages, radiofrequency interference, and acoustic noise. Additionally, corona discharges can easily form streamers, destructive regions of high current, particularly in humid air, causing electrical sparking that can damage substrate materials. The ionization process takes place only locally (due to the non-homogenous electric field) due to the great difference in mass between electrons and positively charged ions resulting in only the electrons having the ability to undergo a significant degree of ionizing inelastic collisions at ambient temperatures and pressures. Although there is a very extensive background on electrical discharges, the corona plasma technique for pollution emission control is still a very young interdisciplinary subject. In relation to chemical reactions and discharge physics, the knowledge is very limited and there are not sufficient physical and chemical data to model the process. It is also very hard to predict the final byproducts. Generally speaking, the main function of corona plasmas in pollution control is to convert one kind of compound into another one, which may be more easily handled. Although corona electrical discharges are well known and have been intensely studied for their technological applications (electrophotography, electroprecipitation, etc.) papers about the effect of coronas on organic matter are recent and scarce. Yang [2] and Mok [3] reported that the phenol removal rate increased with longer release time and that raising the peak voltage was helpful for phenol degradation. They clarified that voltage development could expand the electric field intensity distribution, creating larger amounts of diverse radicals and active species. The liberation of these species in water produces hydroxyl radicals $\left(\mathrm{OH}^{\bullet}\right)$ and hydrogen atoms $(\mathrm{H})$ from water molecules. Under humid conditions an air corona discharge creates ozone $\left(\mathrm{O}_{3}\right)$, singlet oxygen $(\mathrm{O})$, hydrogen peroxide $\left(\mathrm{H}_{2} \mathrm{O}_{2}\right)$ and hydroperoxyl radical $\left(\mathrm{HO}_{2}\right)$ with more capability of oxidizing phenol into lower atomic weight species like carboxylic acids or carbon dioxide. Additionally, Njatawidjaja [4] proposed that $\mathrm{H}_{2} \mathrm{O}_{2}$ and $\mathrm{O}_{3}$ were delivered with air or oxygen bubbles in the reactors, showing the vital role of active radicals in contaminant disintegration reactions. Numerous studies have reported that ozone is created during the plasma treatment process, and the UV radiation could also enhance the disintegration of organic pollutants by $\mathrm{O}_{3}$ and $\mathrm{OH}^{\bullet}$. Dojcinovic [5] considered the oxidation of different contaminant materials with DBD plasma and reached the conclusion that degradation routes practical strategies for the feasible elimination of these contaminants can be developed, and around 10 color categories from 13 type of dyes could be destroyed by $95 \%$. The objective of this investigation was to study the utilization of NTP discharges to produce active radicals as a basis for a special 
industrial wastewater treatment processes. Experimental estimations were done to focus on the impact of the concentration of diverse salts on the efficiency of the dye decolorization process in the presence of NTP discharges. In addition, the essential reactive species which are responsible for the oxidation of organic dye compounds such as $\mathrm{O}_{3}$ generated in treated water and $\mathrm{H}_{2} \mathrm{O}_{2}$ were investigated.

\section{Materials and Methods}

\subsection{Dye Solutions}

The physical properties and chemical structure of the Acid Blue 25 dye used in our experiments are given in Table 1 [6].

Table 1. Physical properties and chemical structure of the dye used.

\begin{tabular}{cc}
\hline Name & Acid Blue 25 Dye \\
\hline Color: & Blue \\
Physical State and appearance & $416.382 \mathrm{~g} / \mathrm{mol}$ \\
Molecular Weight & $416.044287 \mathrm{~g} / \mathrm{mol}$ \\
Exact/Monoisotopic Mass & $138 \AA^{2}$ \\
Surface Area & 29 \\
Atom Count & $600 \mathrm{~nm}^{2}$ \\
UV absorption $\left(\lambda_{\max }\right)$ & \\
Molecular formula & \\
Molecular Structure &
\end{tabular}

\subsection{Non-Thermal Plasma Reactor}

High voltage and a ground electrode were applied above the surface of the dye solution to produce a corona discharge between two high voltage electrodes and the ground plate for degradation of Acid Blue 25 dye. A computerized chemical continuous tank reactor was used as corona reactor in our system to easily control the solution temperature using the reactor shell. The dimensions of the reactor were $100 \mathrm{~mm}$ diameter and $180 \mathrm{~mm}$ height, with an external shell diameter of $120 \mathrm{~mm}$, as presented in Figures 1 and 2.

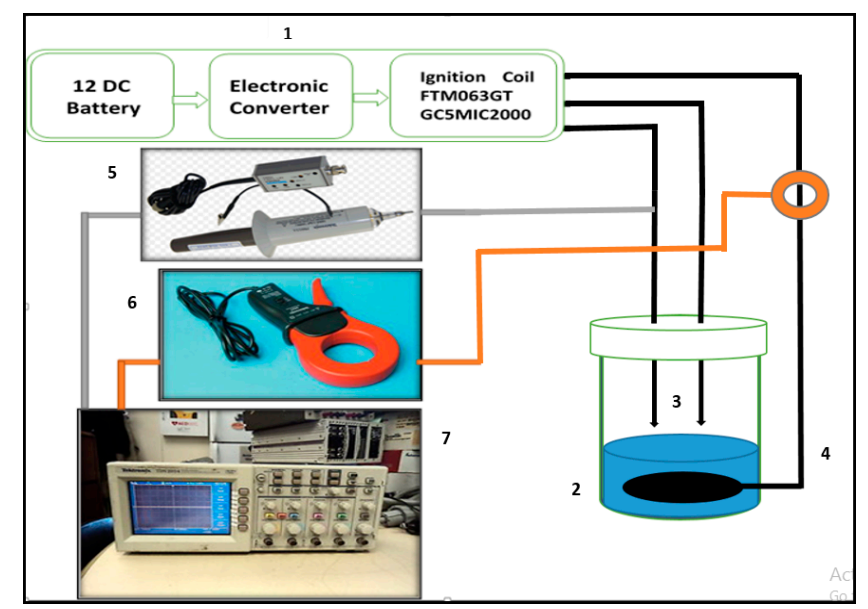

Figure 1. Diagram of the experimental arrangement: 1-Pulsed source; 2-Shell reactor; 3-Pin; 4-Ground; 5-Voltage sensor; 6-Current sensor; 7-Oscilloscope. 


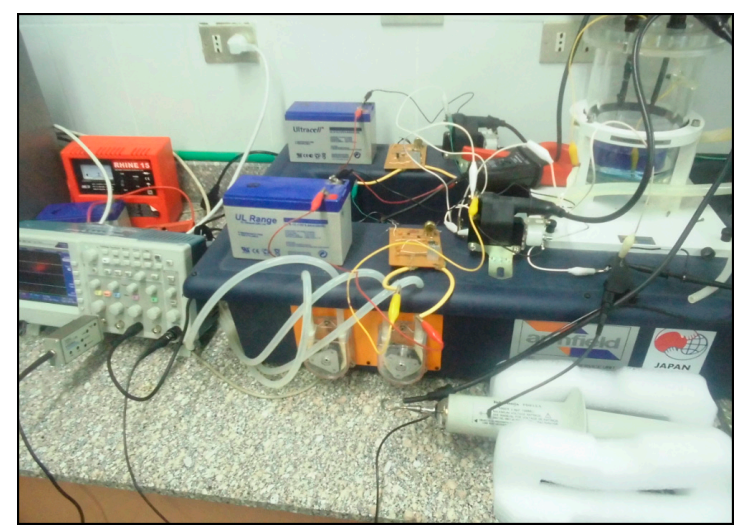

Figure 2. Plasma treatment system using corona discharge.

The width of the pin is $1 \mathrm{~mm}$, its length is $30 \mathrm{~mm}$ and the distance between the two pins is $5 \mathrm{~mm}$. Furthermore, the ground dimension was $0.2 \times 60 \times 50 \mathrm{~mm}$ [7,8]. A high voltage of $15 \mathrm{kV}$ generated by an ignition coil was connected with the dual pin terminal. A P6015A high voltage sensor (Tektronix, Beaverton, OR, USA) was utilized to measure the high voltage waveforms. A Tektronix A6021 current sensor is utilized for the current waveforms. A Tektronix TDS2014 oscilloscope is utilized to display the waveforms. Figure 3 shows the waveforms generated from the ignition coil with period time $10 \mathrm{~ms}$, frequency $100 \mathrm{~Hz}$, negative width $1.376 \mathrm{~ms}$, positive width $8.615 \mathrm{~ms}$ and rise time equal to $70.46 \mu \mathrm{s}$.

The steel electrodes of the two pins and the rectangular ground plate are isolated by a $0.5 \mathrm{~cm}$ air gap distance as the optimum separation gap that was determined previously using software programs [9-12]. A U-3900 UV spectrophotometer (Hitachi, Chiyoda, Tokyo, Japan) was used to measure the dye solution absorption at $600 \mathrm{~nm}$ wavelength before and after the experiments. The pulsed high voltage unit that was utilized as a part of the designed plasma treatment system was comprised from a PWM circuit based on a 555 timer and a model FTM063GT-GC5MIC2000 ignition coil. The utilized PWM circuit and its electronic diagram are illustrated in Figure 3. The operation of the PWM circuit begins with the circuit being powered up, which starts the oscillator cycle and transfers its yield to the capacitor $C_{1}$ to be charged through the right half of $R_{1}$ and diode $D_{2}$. At the point when $C_{1}$ voltage reaches $2 / 3$ of $+V$, the edge is initiated, which thus causes the yield, and releases the capacitor $C_{1}$. As the capacitor $C_{1}$ begins to release through the left half of $R_{1}$ and $D_{1}$ the voltage on $C_{1}$ falls beneath $1 / 3$ of $+V$, and the cycle restarts. Capacitor $C_{1}$ charges through one side of $R_{1}$ and releases through the other side. The aggregate of the charge and release resistance is dependably the same; along these lines the wavelength of the yield sign is consistent and just the obligation cycle fluctuates with $R_{1}$. The general recurrence of the PWM signal in this circuit is dictated by the estimations of $R_{1}$ and $\mathrm{C}_{1}$.

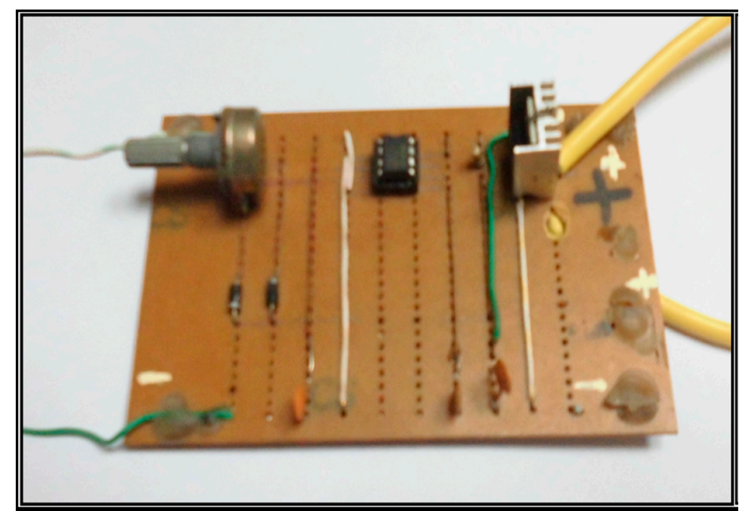

Figure 3. Cont. 


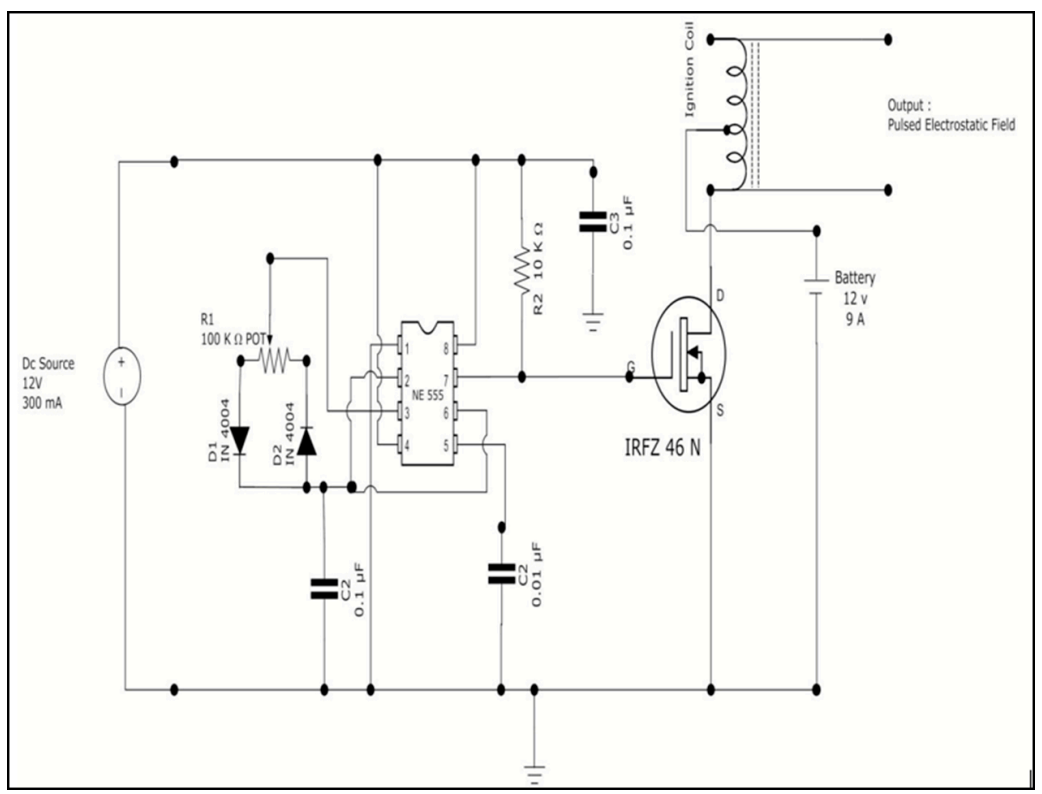

Figure 3. PWM Circuit Based on the 555 Timer.

The work of the IRFZ46N MOSFET relies upon the 555 clock signal, when the MOSFET work is utilized for the isolated DC source and operates the ignition loop. Ignition loops are utilized in automobiles to create the sparks which start the burning of the fuel-air blend in the chambers.

An ignition coil is similar to a transformer comprised of an iron center with an essential and auxiliary twisting. The proportion of auxiliary and essential turns is 100:1. Two windings are associated to one side and the auxiliary is naturally grounded. The most extreme voltage difference achievable in this manner is about $60 \mathrm{kV}$, which is sufficient to jump a $10 \mathrm{~cm}$ air hole. Various arrangements of double high-voltage electrodes have been set up and examined experimentally for their influence on the decolorization process of Acid Blue dye. A high voltage of $15 \mathrm{kV}$ peak output was applied to the pin electrode with a frequency of $100 \mathrm{~Hz}$, period time of $10 \mathrm{~ms}$, rise time equal $70.46 \mu \mathrm{s}$, positive width $8.615 \mathrm{~ms}$ and negative width $1.376 \mathrm{~ms}$. The waveform of the IRFZ46N MOSFET switch signal feed, the output voltage and corona current are shown in Figure 4. Figure 5 illlustrates the non-thermal plasma region in the corona reactor.

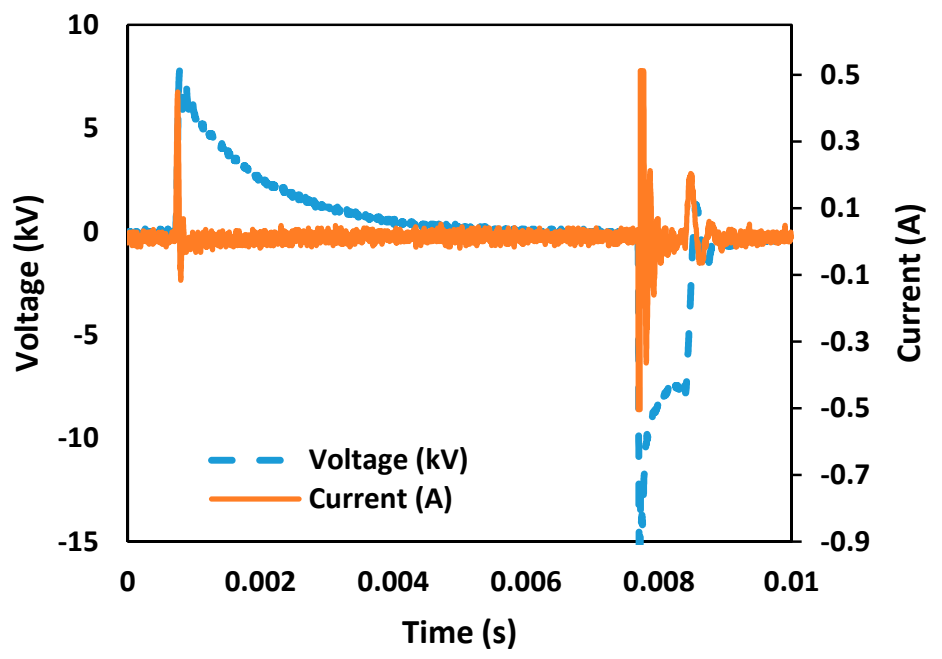

Figure 4. Cont. 


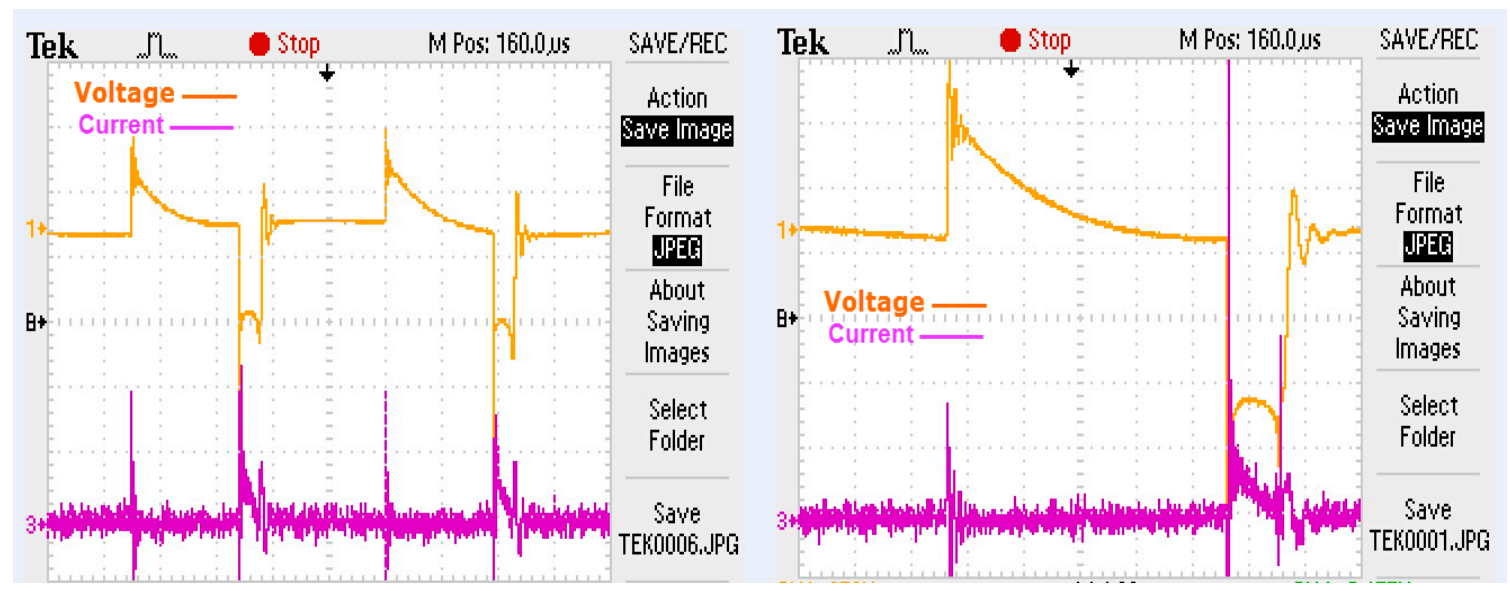

Figure 4. Voltage and current waveform output from the ignition coil.

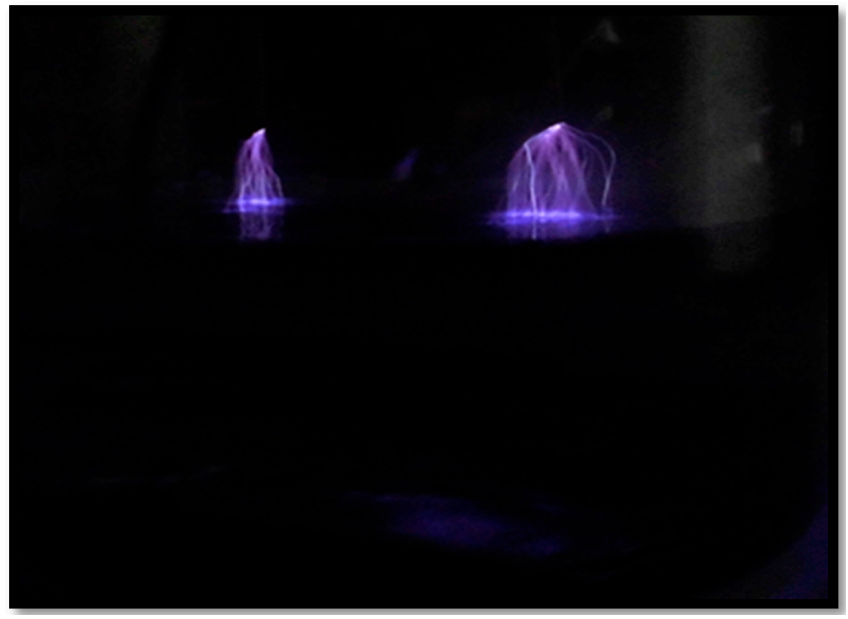

Figure 5. Discharge above the surface of dye solution.

The percentage of the dye removal was calculated from the difference in the dye absorption before and after the experiments [13-15]:

Decolorization Efficiency $(\mathrm{D} \%)=(($ Initial absorption $(\mathrm{Ai})-$ Absorption after treatment time $\mathrm{t}(\mathrm{At})) /$ Initial absorption $(\mathrm{Ai})) \times 100$

\section{Results and Discussion}

The non-thermal plasma (NTP) corona discharge in air is limited to a very small zone in the vicinity of the small radius wire. Various physical processes occur in the corona zone; their modeling is far too complex to be considered when addressing most situations of practical interest. To understand the mechanisms of corona discharge and generation of ozone, the active radicals present and the field and voltage in the gap space between two electrodes should be known. In order to optimize a corona device, the onset voltage and electric field should be determined by the voltage and field distribution [16]. A 3D model was used to determine the optimum gap and thickness of ground plate for $15 \mathrm{kV}$. During the non-thermal plasma process, a huge amount of radicals were created. The degradation of water molecules produced $(\mathrm{OH} \bullet)$ and $(\mathrm{H})$ in the treated solution. The experimental work was focused on the impact of diverse salt concentrations on the efficiency of the decolorization process in the presence of the NTP. In addition, the effects of the essential reactive species produced such as $\mathrm{O}_{3}$ and $\mathrm{H}_{2} \mathrm{O}_{2}$ on the oxidation of organic dyes were investigated. 


\subsection{Impact of the Presence of Diverse Salts in the Dye Solutions}

The influence of the presence of various salts associated with the dye solutions such as $\mathrm{KCl}, \mathrm{NaCl}$, $\mathrm{CaCl}_{2}$ and $\mathrm{AlCl}_{3}$ on the dye decolorization was examined and monitored through the variation of the solution conductivity. In contaminated water, the current flow in the water solution is due to the movement of ions inside the water instead of the movement of electrons like in a metal. Accordingly the influence of presence of different ions at the wastewater is very important. Clean water has a relative steady dielectric constant value of $78.4\left(25^{\circ} \mathrm{C}\right)$ and an electric conductivity of $44.29 \mu \mathrm{S}$ $\left(25^{\circ} \mathrm{C}\right)$ [17]. The salts were added to the dye solution at various molar concentrations $(2,1.5,1,0.5$, 0.25 and $0.1 \mathrm{M}$ ). The color removal efficiency has been estimated for the various studied salts after a treatment time of $35 \mathrm{~min}$. Figures 6-11 illustrate the change of decolorization effectiveness with increasing molar concentration of $\mathrm{KCl}, \mathrm{NaCl}, \mathrm{CaCl}_{2}$ and $\mathrm{AlCl}_{3}$ individually. It is seen from the figures that the presence of $\mathrm{KCl}, \mathrm{NaCl}$ and $\mathrm{AlCl}_{3}$ with the organic dye pollutant has a positive impact on the Acid Blue 25 dye decolorization process. However, the presence of $\mathrm{CaCl}_{2}$ decreased the decolorization effectiveness. It was evident from the figures that $\mathrm{AlCl}_{3}$ has a strong influence on the Acid Blue decolorization process, as the presence of $\mathrm{Cl}^{-}$ions also produces an oxidation potential that enhances the dye degradation process.

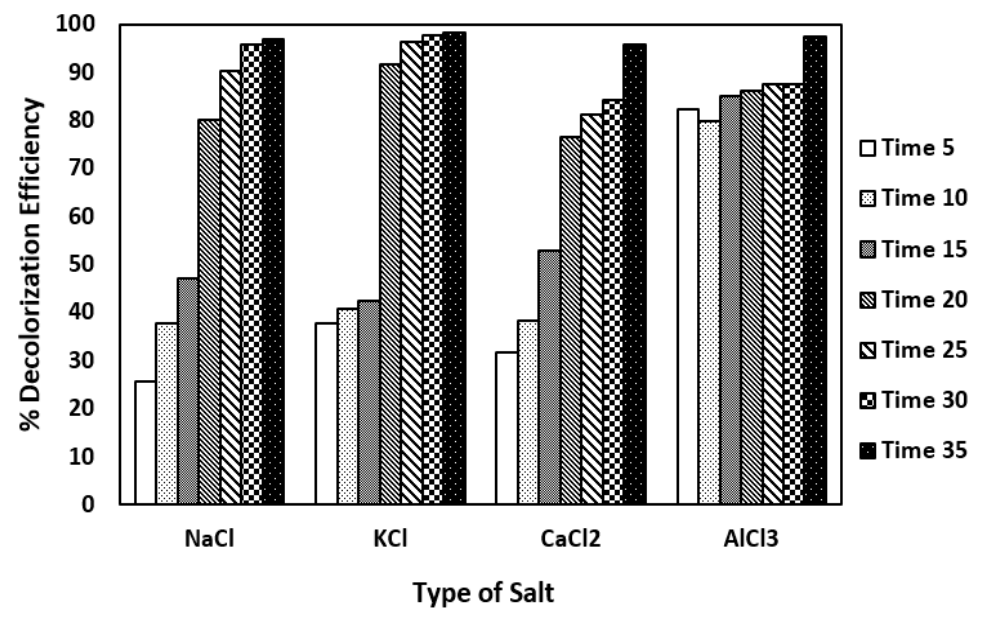

Figure 6. Decolorization efficiency in the presence of $\mathrm{NaCl}, \mathrm{KCl}, \mathrm{CaCl}_{2}$, and $\mathrm{AlCl}_{3}$ salts at $0.1 \mathrm{M}$ concentration.

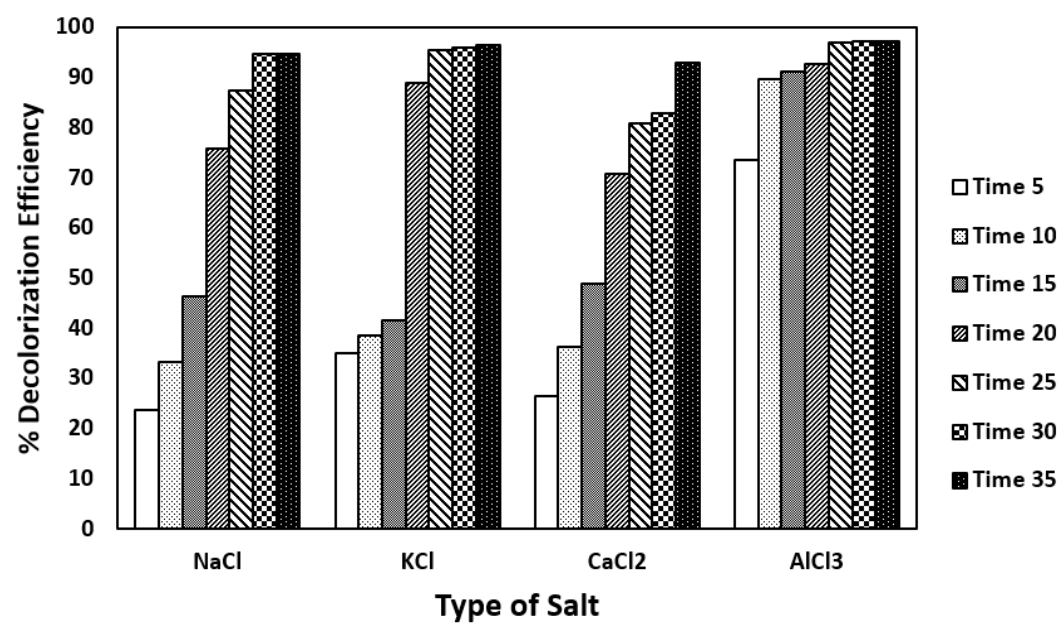

Figure 7. Decolorization efficiency in the presence of $\mathrm{NaCl}, \mathrm{KCl}, \mathrm{CaCl}_{2}$, and $\mathrm{AlCl}_{3}$ salts at $0.25 \mathrm{M}$ concentration. 


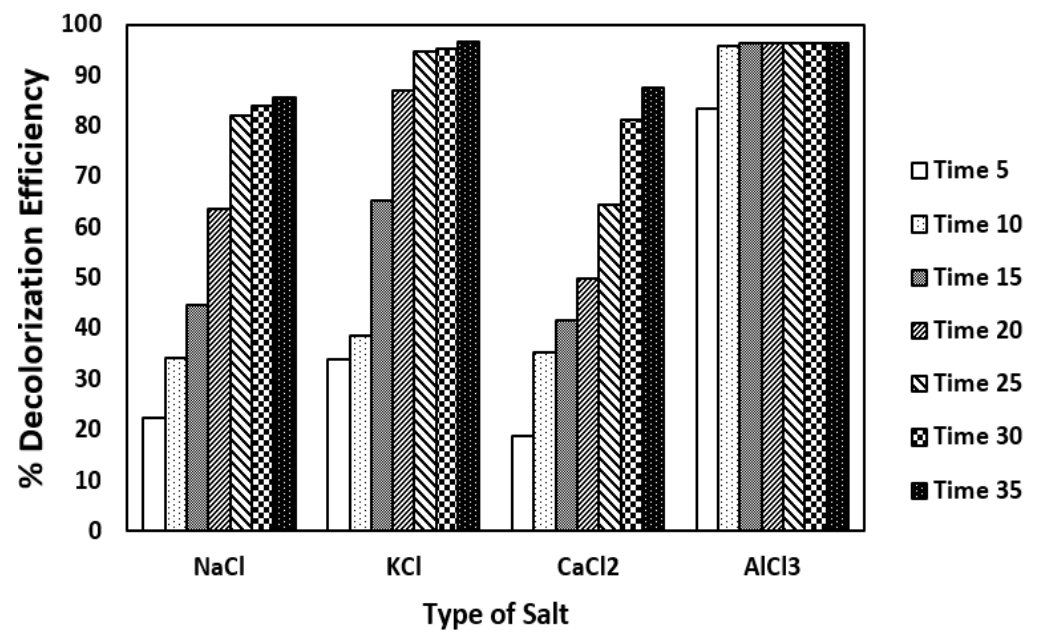

Figure 8. Decolorization efficiency in the presence of $\mathrm{NaCl}, \mathrm{KCl}, \mathrm{CaCl}_{2}$, and $\mathrm{AlCl}_{3}$ salts at $0.5 \mathrm{M}$ concentration.

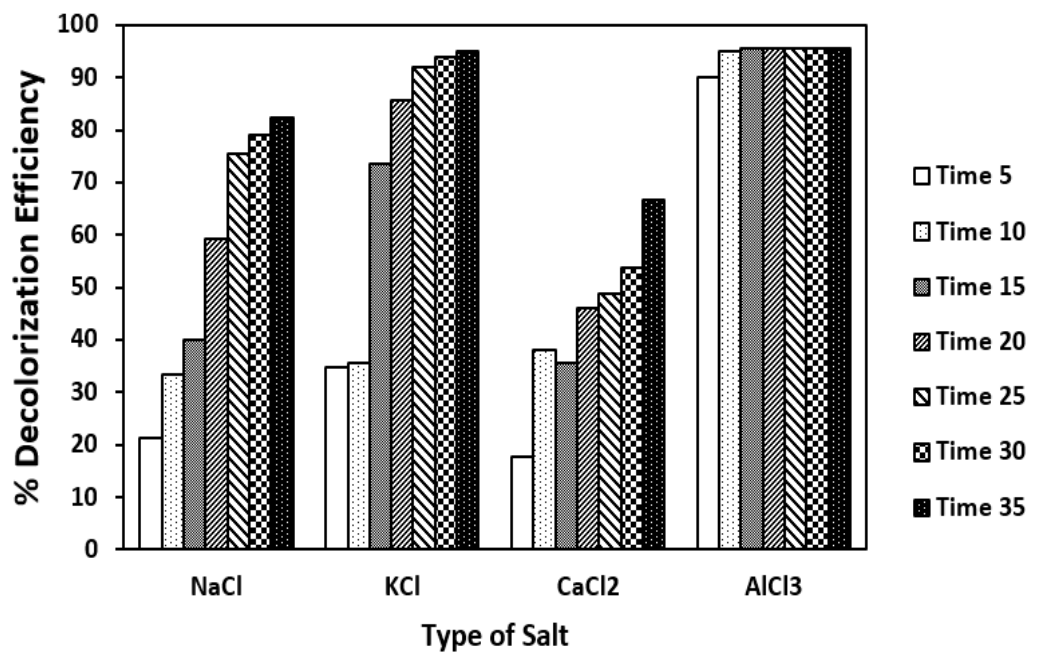

Figure 9. Decolorization efficiency in the presence of $\mathrm{NaCl}, \mathrm{KCl}, \mathrm{CaCl}_{2}$, and $\mathrm{AlCl}_{3}$ salts at $1 \mathrm{M}$ concentration.

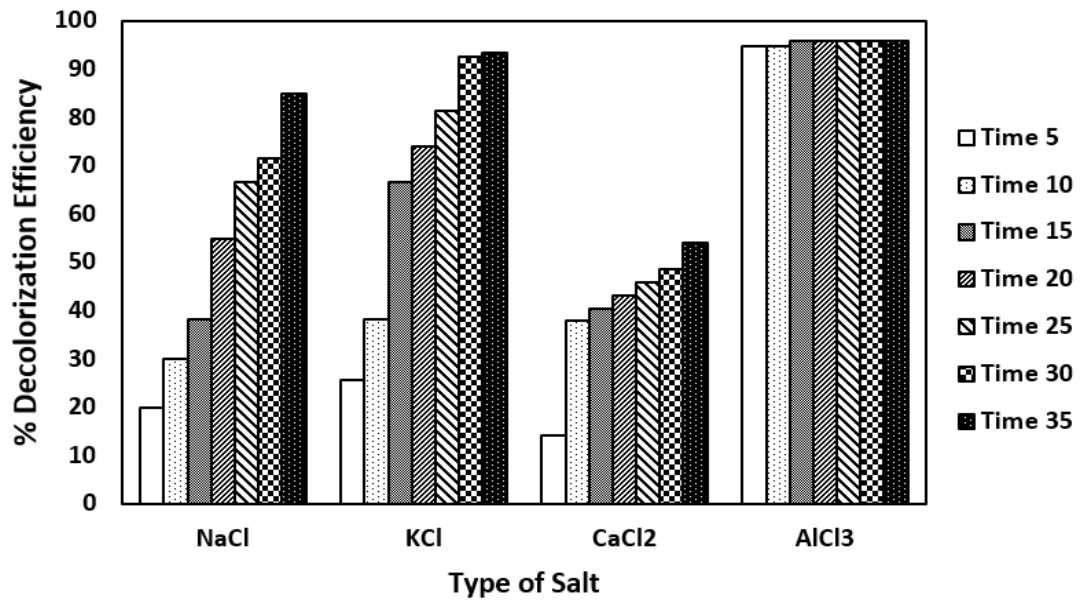

Figure 10. Decolorization efficiency in the presence of $\mathrm{NaCl}, \mathrm{KCl}, \mathrm{CaCl}_{2}$, and $\mathrm{AlCl}_{3}$ salts at $1.5 \mathrm{M}$ concentration. 


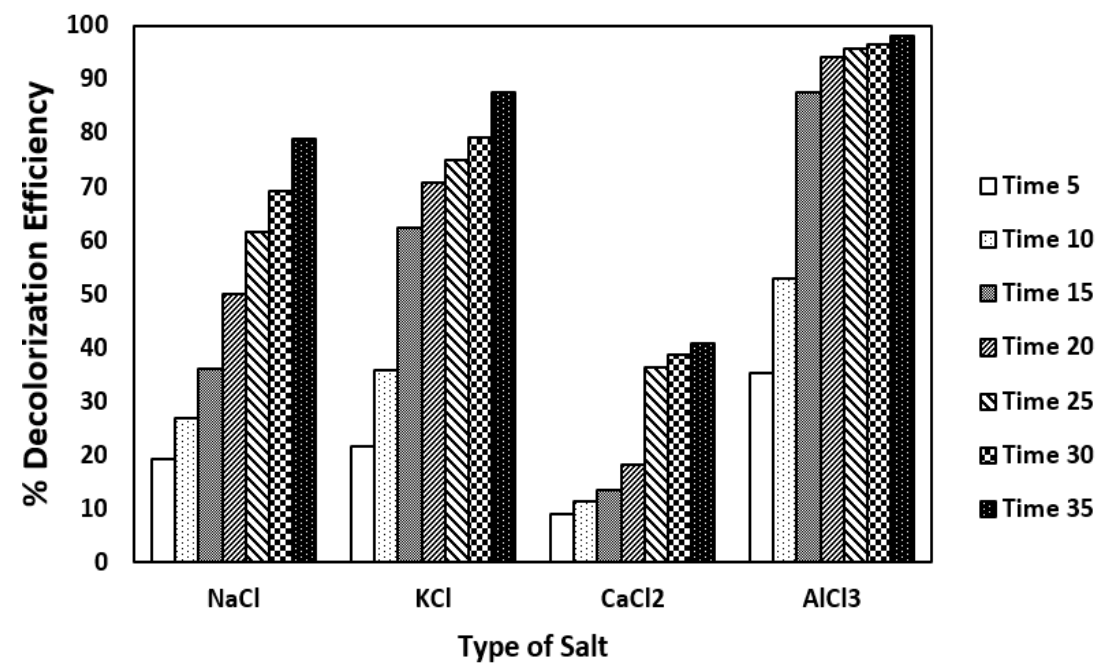

Figure 11. Decolorization efficiency in the presence of $\mathrm{NaCl}, \mathrm{KCl}, \mathrm{CaCl}_{2}$, and $\mathrm{AlCl}_{3}$ salts at $2 \mathrm{M}$ concentration.

In addition, $\mathrm{CaCl}_{2}$ shows a strange behavior as the concentration of $\mathrm{CaCl}_{2}$ increases, whereby the decolorization efficiency was reduced due to the consumption of the active radicals and $\mathrm{H}_{2} \mathrm{O}_{2}$ generated by the action of $\mathrm{Ca}^{2+}$ ions. Moreover, we think that a small amount of $\mathrm{Cl}_{2}$ gas is generated when $\mathrm{AlCl}_{3}$ is utilized at small concentrations which has a negative impact on the dye degradation process, although the influence of the $\mathrm{Cl}_{2}$ gas generated using $\mathrm{AlCl}_{3}$ for dye degradation is extremely small compared with the action of $\mathrm{O}_{3}$ and $\mathrm{H}_{2} \mathrm{O}_{2}$. This observation was confirmed when $\mathrm{CaCl}_{2}$ that also produces $\mathrm{Cl}_{2}$ gas from its degradation is utilized. $\mathrm{NaCl}$ and $\mathrm{KCl}$ have normal behavior as the salt concentrations are changed. To better illustrate this point the diverse solution conductivities in the presence of the four salts are shown in Figure 12 and the discharge energy for every molar concentration is displayed in Figure 13.

As seen in Figure 12 the solution conductivity increased with increasing molar concentration of salts. This behavior is in harmony with the expected results because the presence of salt increases the number of mobile ions that increase the solution conductivity. The results from Figure 12 demonstrate that the energy release increased with the increase in the salt molar concentration; however, the energy release in the presence of $\mathrm{CaCl}_{2}$ and $\mathrm{AlCl}_{3}$ was decreased compared with the cases of $\mathrm{KCl}$ and $\mathrm{NaCl}$.

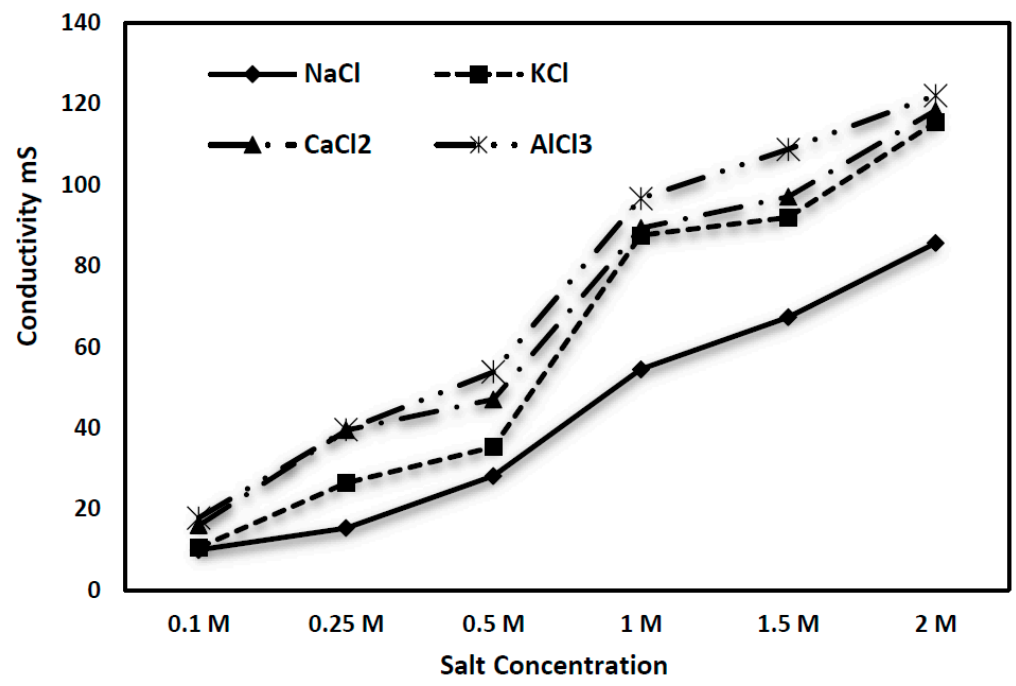

Figure 12. Effects of the presence of $\mathrm{NaCl}, \mathrm{KCl}, \mathrm{CaCl}_{2}$, and $\mathrm{AlCl}_{3}$ salts at various concentrations on solution conductivity. 


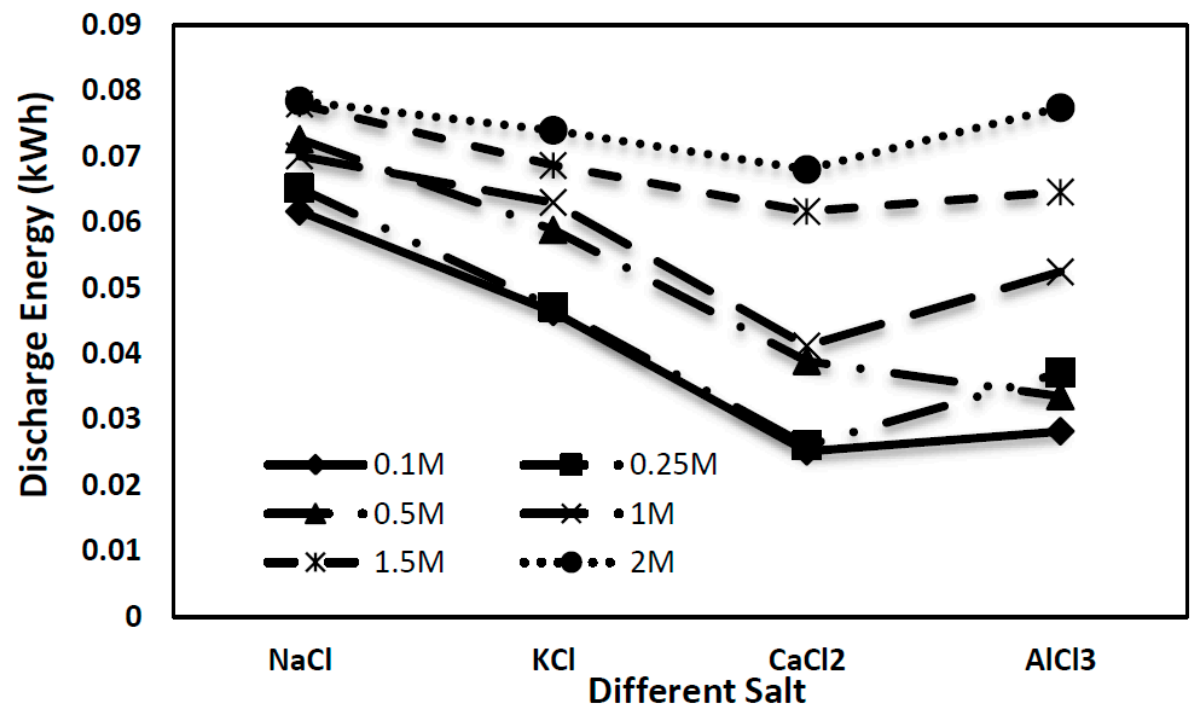

Figure 13. Effects of presence of $\mathrm{NaCl}, \mathrm{KCl}, \mathrm{CaCl}_{2}$, and $\mathrm{AlCl}_{3}$ salts at various concentrations on the energy discharge.

The most significant factor affecting the decolorization process is the discharge power. Any wastewater treatment process should be characterized by its efficiency, cost and time effectiveness. The power needed for the decolorization process was estimated through multiplying the Root Mean Square (RMS) output current and RMS output voltage which are fed to the corona discharge reactor. The input power is equal to $108 \mathrm{~W}$ with a power efficiency of $78.7 \%$ with regard to the power consumption in the ignition coil that was indicated at Figure 13 at the times of 0.001 to $0.007 \mathrm{~s}$. The duration of the decolorization process was selected as $25 \mathrm{~min}$ (1500 s) and the volume of industrial wastewater used was $100 \mathrm{~mL}$.

It's seen from Figure 14 that the discharge was pulsed-wave amplitude-modulated at a rate of $100 \mathrm{~Hz}$. This allowed enough time to reach a steady state electron density during the on time, but, did not allow the electron density to reach zero during the off time because the electron density decay rate in air is slow. The power to the reactor and the magnitude of the voltage and current are plotted in Figures 4 and 14, respectively. We have measured the voltage and current of a pulsed air discharge during glow turn-on and turn-off as shown in Figure 4. The power does not increase monotonically during the turn- on and does not decrease monotonically to zero at discharge turn-off, caused primarily by the external circuitry, and the power becomes negative at discharge turn-off also due primarily to the external circuitry as shown in Figure 14. During this time the electron density and current rise and the effective electron collision frequency decreases. Since the collision frequency acts as an indirect measure of the electron decreases from discharge turn-on. A larger average electron energy might account for some of the noted differences between pulsed and continuous glows [18,19]. Sunka [20] demonstrated that conductivity has no relation to the limit voltage. Also, he indicated that the higher voltage values of solutions with higher conductivity are capable of beginning the electrical discharge. Takahashi [21] established that the discharge-initiating voltage reduces as the path of conductivity action is extended. The improvement in the value of solution conductivity prompts a higher current stream and more compelling ohmic warming allowing vaporization frames. Since electrical discharge initiation disappears before by the water vaporization as considered, the improvement in solution conductivity will more likely lead to electrical discharge advancement and decrease the limit voltage. Looking at the effect of solution conductivity, it was agreed that the rise in solution conductivity prompts the higher power and plasma densities and more extraordinary UV radiation in the center of the electrical discharge. 


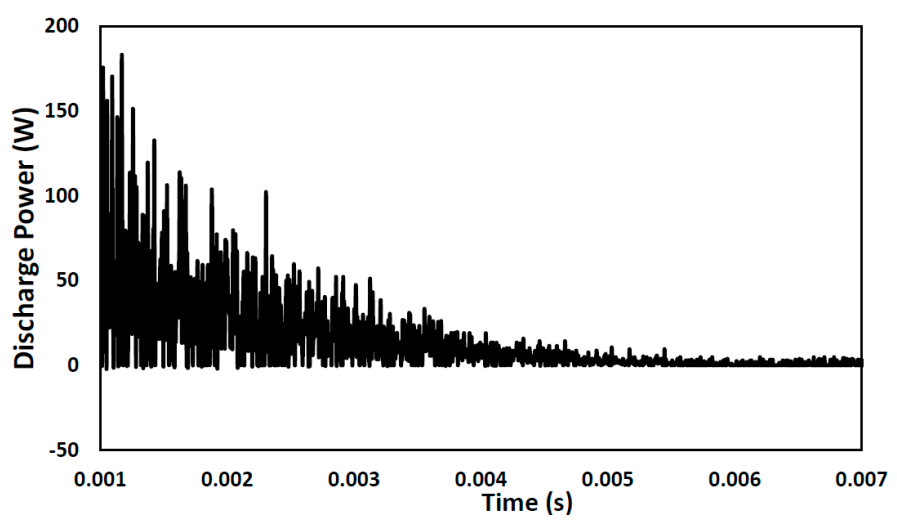

Figure 14. Discharge power with the time for Acid Blue 25 dye during the 0.001-0.007 s.

\section{2. $\mathrm{H}_{2} \mathrm{O}_{2}$ Concentration Measurement}

Hydrogen peroxide is a clear, colorless liquid, slightly more viscous than water. It is totally mixable in water and alcohols. Considering its redox potential, one would suppose hydrogen peroxide would act as a strong oxidizing agent. Many analytical methods use hydrogen peroxide as catalyst. The most common laboratory method used for the determination of hydrogen peroxide concentrations is the permanganate method, which is based upon the oxidizing characteristics of peroxide. In this method, potassium (VII) is reduced to potassium (II) according to reaction of Equation (2) [22,23]:

$$
2 \mathrm{KMnO}_{4}+5 \mathrm{H}_{2} \mathrm{O}_{2}+3 \mathrm{H}_{2} \mathrm{SO}_{4} \leftrightarrow \mathrm{K}_{2} \mathrm{SO}_{4}+2 \mathrm{MnSO}_{4}+8 \mathrm{H}_{2} \mathrm{O}+5 \mathrm{O}_{2}
$$

The overall stoichiometry of the reaction dictates that $10 \mathrm{~mL}$ of $\mathrm{H}_{2} \mathrm{O}_{2}$ withdrawn from the synthetic dye solution after the corona discharge treatment process will react with $5 \mathrm{~mL}$ of $4 \mathrm{~N} \mathrm{H}_{2} \mathrm{SO}_{4}$. The titration process is done under acidic situations. The solution of peroxide was titrated with $0.01 \mathrm{~N} \mathrm{KMnO}_{4}$ until a permanent color absence is observed and then the volume of permanganate is recorded. This experiment was repeated every $10 \mathrm{~min}$ and the concentration of $\mathrm{H}_{2} \mathrm{O}_{2}$ was calculated by Equation (3):

$$
(\mathrm{C} \times \mathrm{V}) \mathrm{KMnO}_{4}=\left(\mathrm{C}^{*} \times \mathrm{V}^{*}\right) \mathrm{H}_{2} \mathrm{O}_{2}
$$

where $\mathrm{C}=$ the concentration of $\mathrm{KMnO}_{4} ; \mathrm{V}=$ the volume of $\mathrm{KMnO}_{4} ; \mathrm{C}^{*}=$ the concentration of $\mathrm{H}_{2} \mathrm{O}_{2}$; $\mathrm{V}^{*}=$ the volume of $\mathrm{H}_{2} \mathrm{O}_{2}$.

$\mathrm{H}_{2} \mathrm{O}_{2}$ is one of significant oxidants produced in NTP. Throughout the current study, $\mathrm{H}_{2} \mathrm{O}_{2}$ was formed in the plasma. Figure 15 shows the variation of $\mathrm{H}_{2} \mathrm{O}_{2}$ concentration over the studied treatment process period. It was indicated that the amount of $\mathrm{H}_{2} \mathrm{O}_{2}$ at the solution increased with the reaction time. This behavior may be due to the decreasing number of dye molecules that needed to be degraded, which enhances the concentration of $\mathrm{H}_{2} \mathrm{O}_{2}$ in the solution.

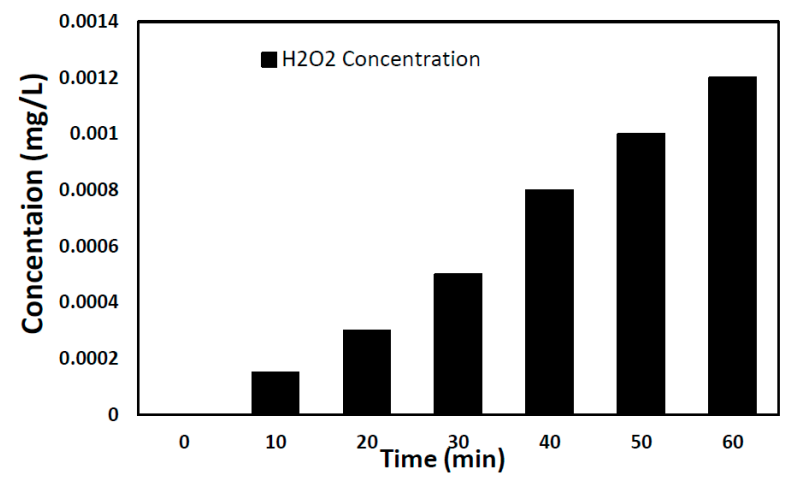

Figure 15. Relation between $\mathrm{H}_{2} \mathrm{O}_{2}$ concentrations with the time. 


\subsection{Ozone Concentration in Treated Water}

Ozone is an inorganic molecule with the formula $\mathrm{O}_{3}$. It is a light blue gas with a particularly noticeable smell. The quantity of $\mathrm{O}_{3}$ in the polluted water was measured using the iodometric technique. For this the ozone produced was absorbed in an alkaline $2 \%$ potassium iodide (KI) solution (70 mL), which was then acidified by adding $5 \mathrm{~mL}$ of $2 \mathrm{~N} \mathrm{H}_{2} \mathrm{SO}_{4}$ solution, to form iodine from the $\mathrm{KI}_{3}$ complex. The obtained iodide shows a blue coloration when $1 \mathrm{~mL}$ of starch solution $(0.5 \%)$, is added and its amount was defined by titrating with $0.001 \mathrm{~N} \mathrm{Na}_{2} \mathrm{~S}_{2} \mathrm{O}_{3}$ solution. The chemical reactions involved, which occur in acid medium, were investigated based on the following Equations (4) and (5) [24,25]:

$$
\begin{gathered}
\mathrm{H}_{2} \mathrm{O}+\mathrm{O}_{3}+2 \mathrm{KI} \rightarrow \mathrm{I}_{2}+2 \mathrm{KOH}+\mathrm{O}_{2} \\
2 \mathrm{Na}_{2} \mathrm{~S}_{2} \mathrm{O}_{3}+\mathrm{I}_{2} \rightarrow \mathrm{Na}_{2} \mathrm{~S}_{4} \mathrm{O}_{6}+2 \mathrm{NaI}
\end{gathered}
$$

For concentrations between 2 and $160 \mathrm{mg} \mathrm{O}_{3} / \mathrm{L}$, the error of the method was determined to be within $1 \%$. The quantity of absorbed ozone was estimated with the following formula $(6)[24,25]$ :

$$
\mathrm{C}=171.6 \times 10^{-3} \times\left(\mathrm{V}_{2} / \mathrm{V}_{1}\right)
$$

where $\mathrm{V}_{1}=$ is the volume of $\mathrm{KI}$ solution $(2 \%)$ and $\mathrm{V}_{2}=$ the volume of $\mathrm{Na}_{2} \mathrm{~S}_{2} \mathrm{O}_{3}$ solution employed in the titration process.

The iodometric method was used for determination the ozone generated in the dye solution during the plasma treatment process, where the sample was measured before and after the plasma treatment process. The ozone in the discharge air is shown in Figure 16. It was evidenced from this figure that the ozone concentration increased with increasing treatment process time and this may be regarded due to the reduction in the amount of dye molecules present in the solution.

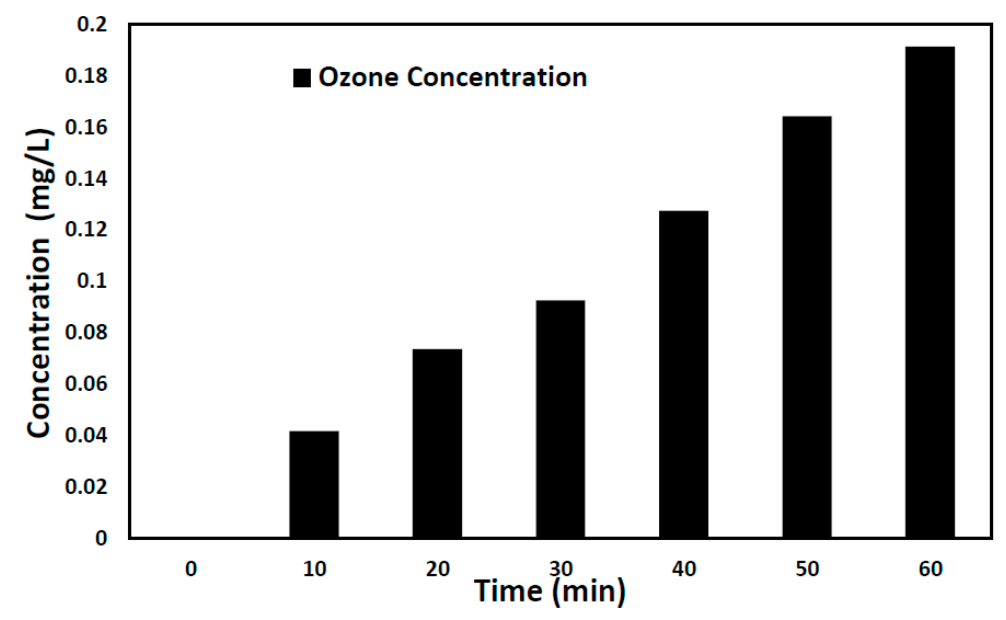

Figure 16. Relation between the generated $\mathrm{O}_{3}$ at treated dye solution with the time.

\subsection{Energy Yield for Decolorization of Acid Blue 25 Dye}

The most important factor for assessing the treatment process is the energy yield which is called G-value (defined as the amounts of radicals produced per $100 \mathrm{eV}$ from the electrical discharge energy input of the process). Another definition for energy yield value is as the quantity of moles of pollutant removed from the solution by one joule of energy supplied to the process, giving G-values dependent upon time or on the streamer length. The energy yield of the polluted dye solution under the pulsed discharge system was ascertained by utilizing the equation of Hayashi [23] and Lukes [24]:

$$
\mathrm{G}=\left(\mathrm{C}_{0} \times \mathrm{V}_{0} \times \mathrm{D} \%\right) /(100 \times \mathrm{P} \times \mathrm{t})
$$


where G: energy yield $(\mathrm{g} / \mathrm{kWh}) ; \mathrm{C}_{0}$ : concentration of the pollutant at $\mathrm{t}=0 ; \mathrm{V}_{0}$ : volume of treated solution; P: power of the reactor $(\mathrm{w})$; $\mathrm{t}$ : time required $(\mathrm{s})$. The energy yield was calculated using Equation (7) with an initial volume of water $V_{0}=100 \mathrm{~mL}$ and initial concentration $\mathrm{C}_{0}=10 \mathrm{ppm}$, where the power of the reactor was calculated from both the electric current and average voltage. The power consumed was calculated from the output voltage and currents. Figures 17-20 illustrate the relations between the energy yield $(\mathrm{g} / \mathrm{kWh})$ and the time for different concentrations of $\mathrm{NaCl}, \mathrm{KCl}, \mathrm{CaCl}_{2}$ and $\mathrm{AlCl}_{3}$ in the presence of $10 \mathrm{mg} / \mathrm{L}$ Acid Blue 25 dye solution. It is noticed that the energy yield increased as the salt concentration is reduced. Obviously, the energy yield for $50 \%$ dye removal at 5 min time is greater in the situation of gas-phase plasma contacting liquid surfaces and the greatest situation can influence numerous hundred grams per kilowatt-hour $(\mathrm{g} / \mathrm{kWh})$.

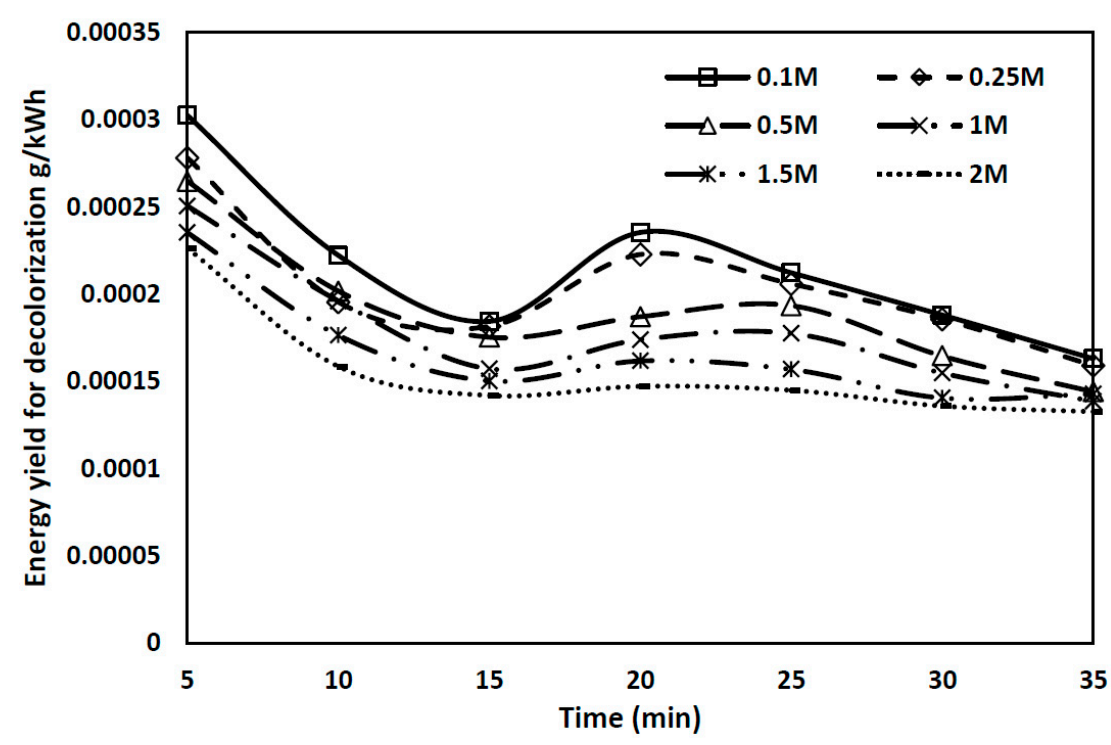

Figure 17. Relation between the energy yield and time at concentration of $\mathrm{NaCl}$ in Acid Blue 25 dye.

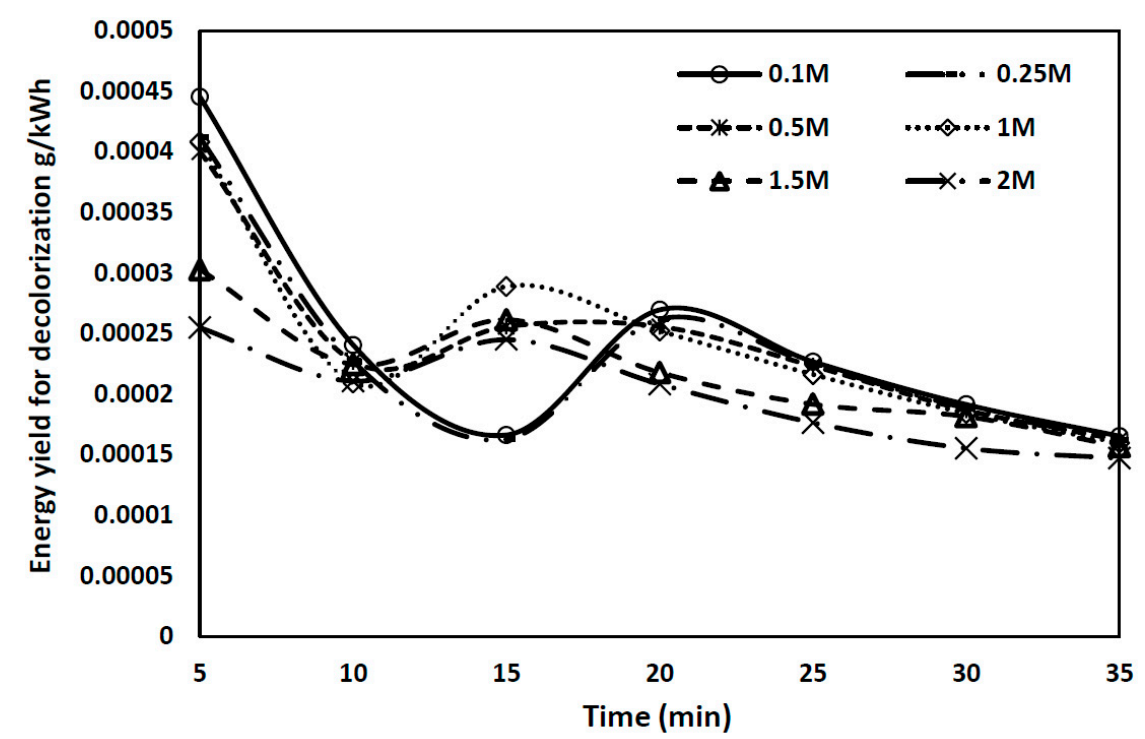

Figure 18. Relation between the energy yield and time at concentration of $\mathrm{KCl}$ in Acid Blue 25 dye. 


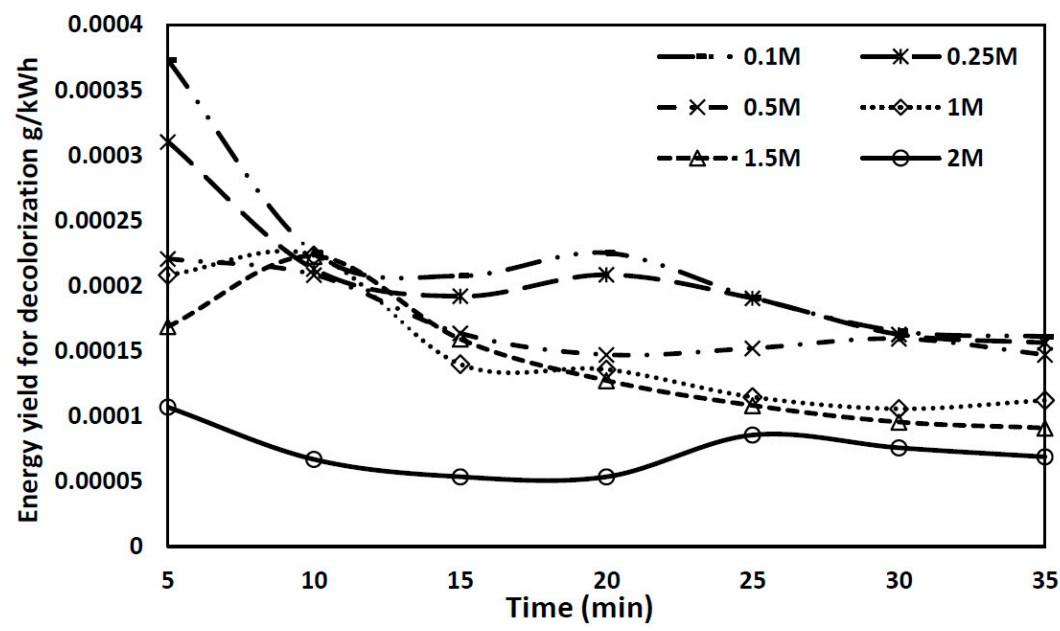

Figure 19. Relation between the energy yield and time at concentration of $\mathrm{CaCl}_{2}$ in Acid Blue 25 dye.

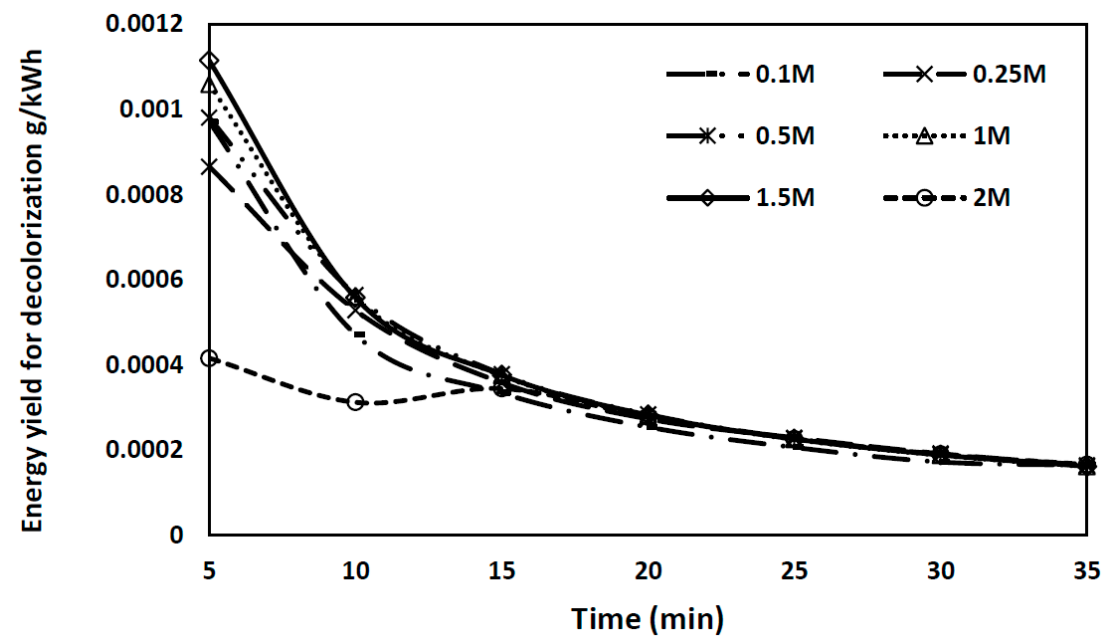

Figure 20. Relation between the energy yield and time at concentration of $\mathrm{AlCl}_{3}$ in $\mathrm{Acid}$ Blue 25 dye.

The relation between the variations in salt concentration against the average energy yield for different types of salts is shown in Figure 21.

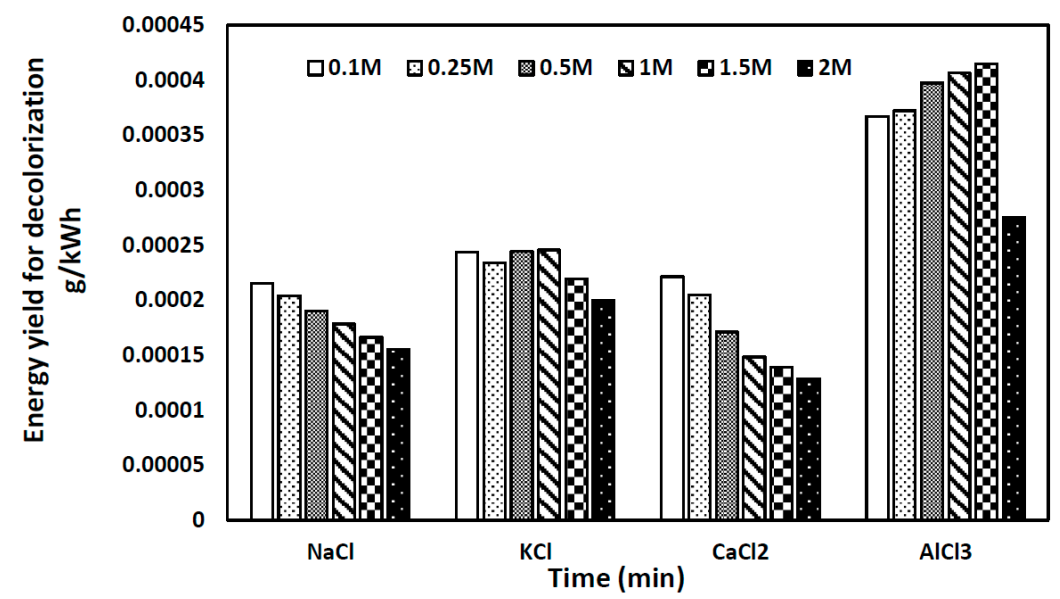

Figure 21. Relation between the variations in salt concentration against average of the energy yield for different type of salts. 
It is noticed from the figure that the energy yield increased at low salt concentration for $\mathrm{NaCl}$ and $\mathrm{CaCl}_{2}$ whereas the $\mathrm{KCl}$ and $\mathrm{AlCl}_{3}$ show a different behavior. The maximum energy yield value was obtained from the figure at $5 \mathrm{~min}$ time of the treatment process.

\subsection{Electrical Energy Per Order (EE/O)}

The electrical energy per order $(\mathrm{EE} / \mathrm{O})$ is a powerful scale-up parameter which measures the treatment rate in a fixed volume of contaminated water as a function of the applied specific energy dose. For low pollutant concentrations, the EE/O value can be derived as described in this section. The EE/O value can be utilized to compare the energy efficiency of different systems. For instance, the assessment of the treatment overheads represents one of the aspects which need more consideration. There are various vital elements in selecting a waste-treatment innovation, including financial matters, economy of scale, regulations, operation and strength (adaptability to change/upsets). Generally, all of these aspects are vital, and a financial aspect is regularly central. The characteristic measure of the electrical performance of the treatment processes is the energy yield $(\mathrm{g} / \mathrm{kW}$ or $\mathrm{eV} / \mathrm{mol})$ or the $(\mathrm{EE} / \mathrm{O})$, which is often used for many chemical degradation or oxidation processes. The EE/O presented in this article gives a straight connection to the electrical efficiency in an advanced oxidation process (AOP) system. The EE/O allows a fast definition of the energy cost and a sign of the total power consumed that is necessary for a detailed application. The EE/O is defined as the electrical energy in kilowatt hours $(\mathrm{kWh})$ needed to degrade or oxidize a polluted $\mathrm{C}$ by one order of magnitude in $1 \mathrm{~m}^{3}(1000 \mathrm{~L})$ of polluted water or air. EE/O evaluation (in $\mathrm{kWh} / \mathrm{m}^{3}$ ) can be obtained from the following equation:

$$
\mathrm{E}(\mathrm{E} / \mathrm{O})=(\mathrm{P} \times \mathrm{T} \times 1000) /\left(60 \times \mathrm{V} \times \log \left(\mathrm{C}_{\mathrm{i}} / \mathrm{C}_{\mathrm{f}}\right)\right)
$$

where $\mathrm{P}=$ power $(\mathrm{kW}) ; \mathrm{V}=$ volume of water $(\mathrm{L}) ; \mathrm{T}=$ treatment time $\mathrm{t}(\mathrm{min}) ; \mathrm{C}_{\mathrm{i}}=$ initial concentrations $\left(\mathrm{mol} \cdot \mathrm{L}^{-1}\right) ; \mathrm{C}_{\mathrm{f}}=$ final concentrations $\left(\mathrm{mol} \cdot \mathrm{L}^{-1}\right)$.

The EE/O was calculated using Equation (8) with an initial volume of water $\mathrm{V}_{0}=100 \mathrm{~mL}$ and initial concentration of $\mathrm{C}_{\mathrm{i}}=10 \mathrm{ppm}$ and final dye concentration at each studied temperature. Figures 22-25 show the relations between the EE/O and the treatment time under different concentrations of $\mathrm{NaCl}, \mathrm{KCl}, \mathrm{CaCl}_{2}$ and $\mathrm{AlCl}_{3}$ in the presence of Acid Blue 25 dye solution.

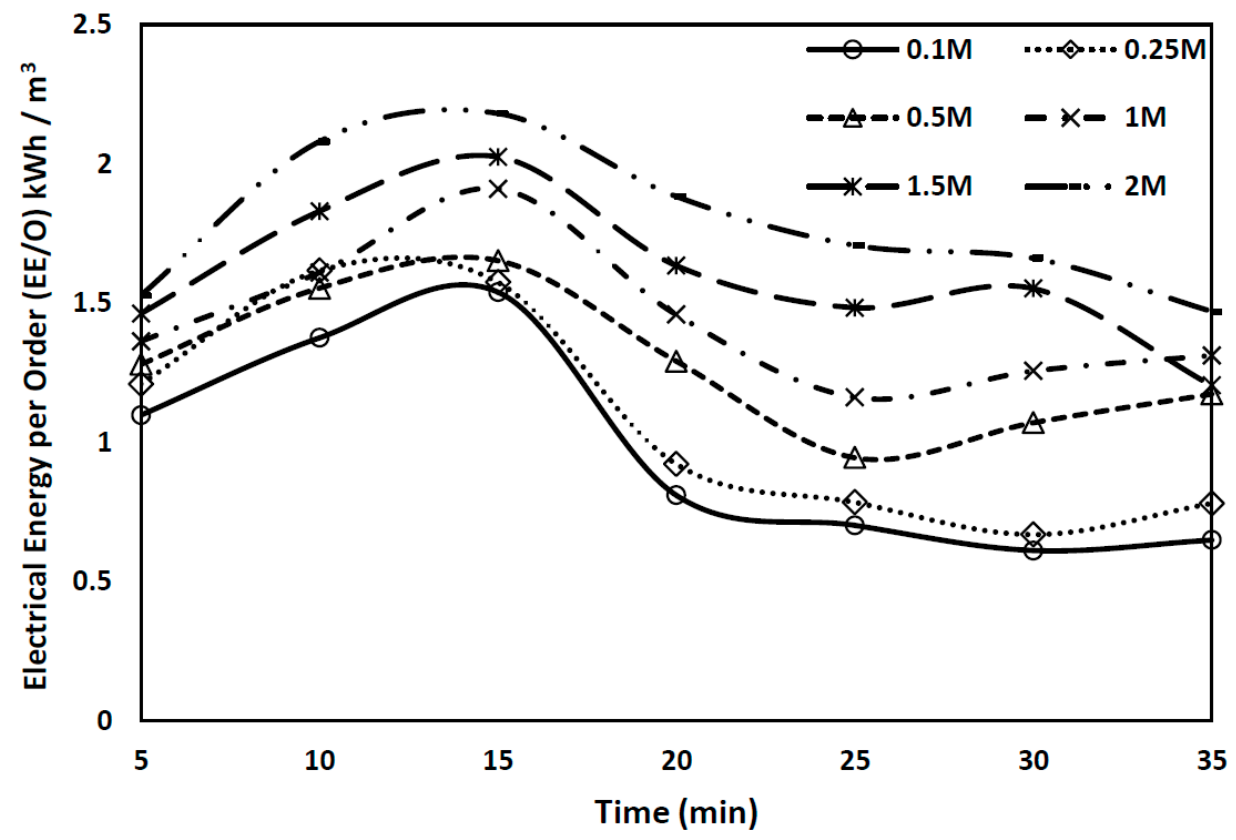

Figure 22. Relation between the $\mathrm{EE} / \mathrm{O}$ and time for different concentrations of $\mathrm{NaCl}$. 


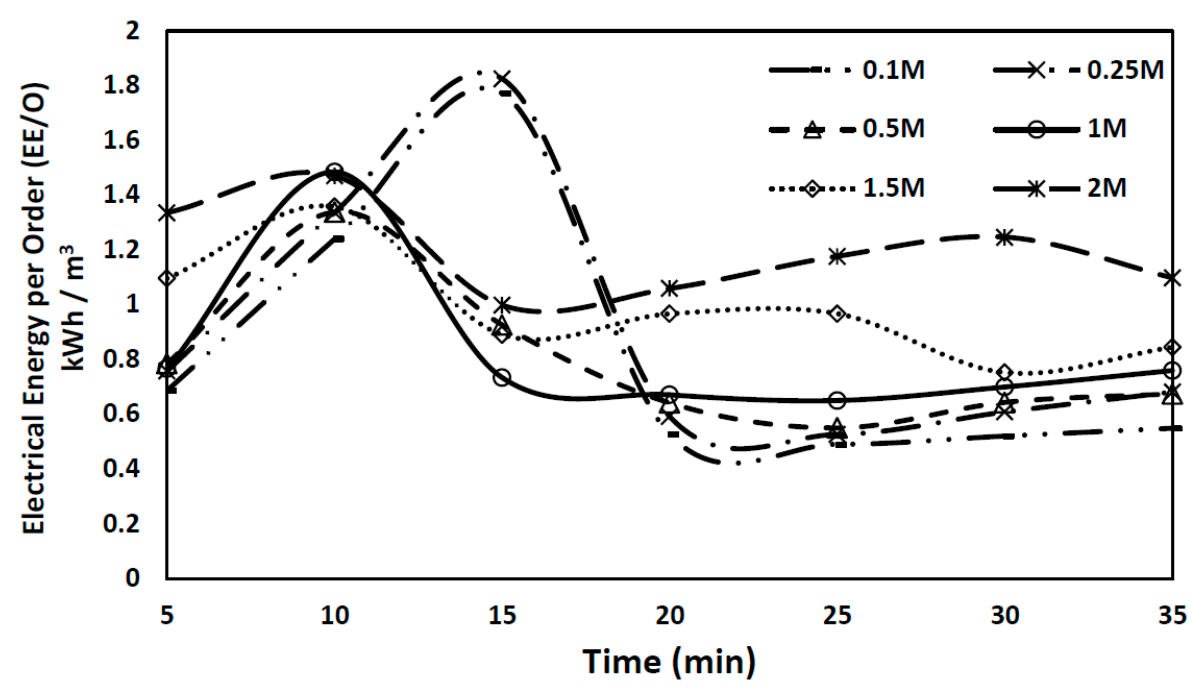

Figure 23. Relation between $\mathrm{EE} / \mathrm{O}$ and time for different concentrations of $\mathrm{KCl}$.

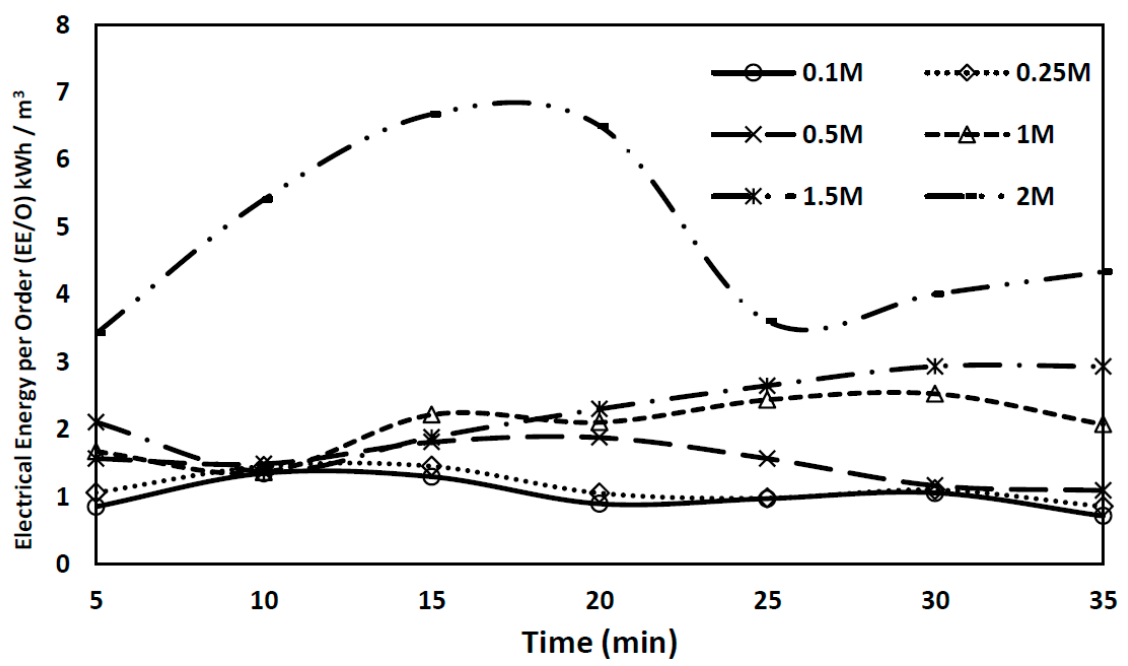

Figure 24. Relation between $\mathrm{EE} / \mathrm{O}$ and time for different concentrations of $\mathrm{CaCl}_{2}$.

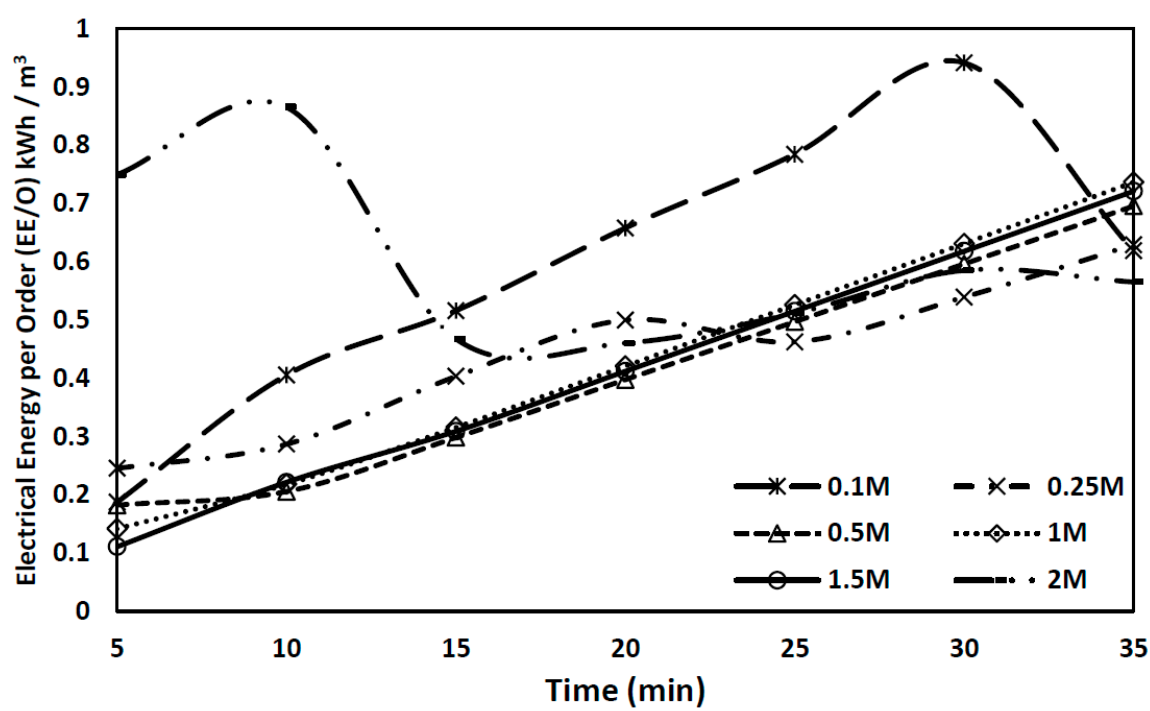

Figure 25. Relation between $\mathrm{EE} / \mathrm{O}$ and time for different concentrations of $\mathrm{AlCl}_{3}$. 
It is noticed that the EE/O increases with increasing molar concentration of the salts $\mathrm{NaCl}, \mathrm{KCl}$, $\mathrm{CaCl}_{2}$ and $\mathrm{AlCl}_{3}$ from $0.1 \mathrm{M}$ to $2 \mathrm{M}$ during the time of treatment. Adoption of the EE/O will let the industry and potential workers have a standardized objective basis for assessment. The EE/O behavior for the four different salts was similar for $\mathrm{NaCl}$, and $\mathrm{KCl}$, however in the case of $\mathrm{CaCl}_{2}$ and $\mathrm{AlCl}_{3}$ the behaviors are different. Regarding the first behavior seen with $\mathrm{NaCl}$ and $\mathrm{KCL}$, the EE/O increases with time due to the fact more energy is needed for dye degradation and generation of the active radicals $\left(\mathrm{H}_{2} \mathrm{O}_{2}, \mathrm{O}_{3}\right.$ and $\left.\mathrm{OH}\right)$ for $15 \mathrm{~min}$ time and the EE/O reduces with time as the amount of radicals generated is increasing and the dye resistance for degradation reduces, so that amount of energy is reduced. In contrast, the behavior of $\mathrm{EE} / \mathrm{O}$ under the influence of $\mathrm{CaCl}_{2}$ is constant during the whole time but at a higher value of $\mathrm{EE} / \mathrm{O}$ compared with $\mathrm{NaCl}$ and $\mathrm{KCl}$ due to the negative influence of $\mathrm{Ca}$ on the active radicals so the dye degradation needs more energy for decolorizing the dye. On the other hand, the $\mathrm{AlCl}_{3}$ has a distinguishable behavior in that the $\mathrm{EE} / \mathrm{O}$ starts by increasing because its $\mathrm{EE} / \mathrm{O}$ increases with time but with a lower $\mathrm{EE} / \mathrm{O}$ value than $\mathrm{CaCl}_{2}$ due to the influence of the high $\mathrm{Cl}$ ion concentration. Furthermore, the relation between the variations in salt concentration against average of the EE/O for different type of salts is shown in Figure 26. It is noticed from the figure that the EE/O increased at high salt concentration for all salts.

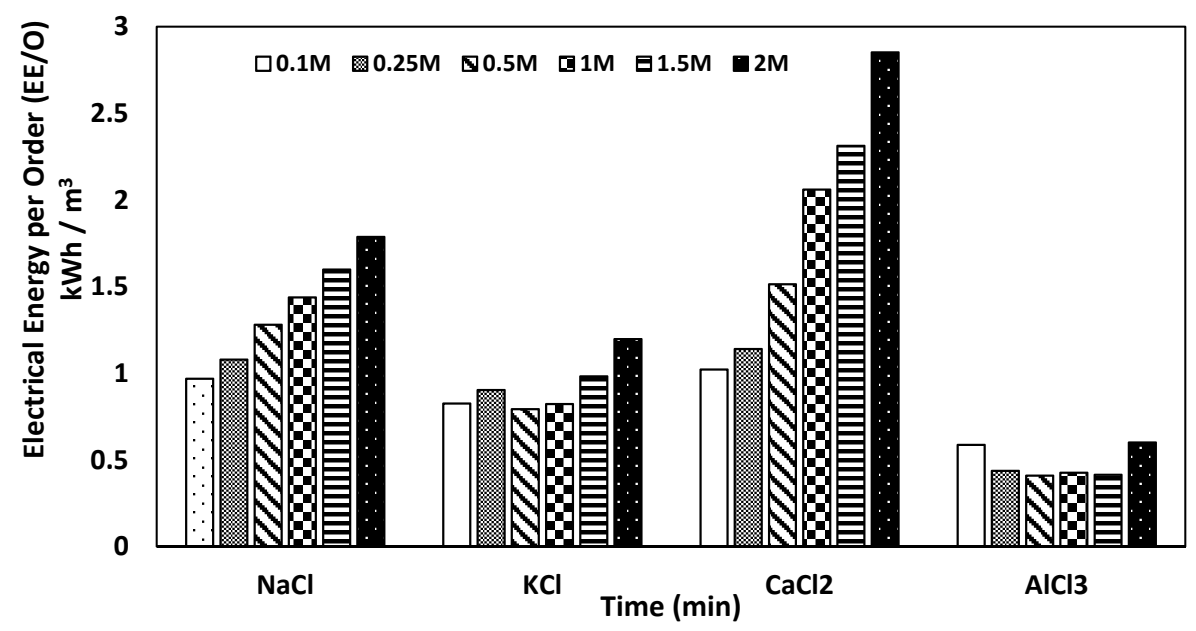

Figure 26. Relation between the variations in salt concentration against average of the EE/O for different types of salts

We compared the EE/O with conventional advanced oxidation of these dyes, where the advanced oxidation processes (AOPs) include $\mathrm{UV} / \mathrm{O}_{3}, \mathrm{UV} / \mathrm{H}_{2} \mathrm{O}_{2}$, Fenton, photo-Fenton, persulfate, non-thermal plasmas, sonolysis, photocatalysis, radiolysis, electron beam, corona discharge, and supercritical water oxidation processes [26]. It is apparent that the ozonation process proved to be the best option in terms of energy consumption and decolorization of dye solution. The energy consumption and cost of the treatment process increases as the initial dye concentration is increased, and as well as with an increase in the applied dose. EE/O parameters are inversely proportional to fundamental efficiency, the quantum yield of generation of active $\mathrm{OH}$ radicals. For $\mathrm{UV} / \mathrm{H}_{2} \mathrm{O}_{2}$ and $\mathrm{UV} / \mathrm{H}_{2} \mathrm{O}_{2} /$ biosorbent the total electrical energy required is $3.428 \mathrm{kWhm}^{-3}$ and $2.504 \mathrm{kWhm}^{-3}$, respectively. From the economical point of view, the $\mathrm{H}_{2} \mathrm{O}_{2} / \mathrm{UV}$ process electrical energy for $\mathrm{RBB}$ decolorization (EEO $=59.25 \mathrm{kWhm}^{-3}$ ) was much higher than by the $\mathrm{UV} / \mathrm{H}_{2} \mathrm{O}_{2} /$ biosorbent process $\left(\mathrm{EEO}=40 \mathrm{kWhm}{ }^{-3}\right.$ ). For a full-scale system, these costs strongly depend on the flow rate of the effluent and the reactor as well as the nature of the effluent [27]. Comparing the EE/O required using different oxidation processes studied in the literature with our corona discharge oxidation process for dye degradation, it was indicated that our process required an average EE/O value of $2 \mathrm{kWhm}^{-3}$. This value is comparable with the $\mathrm{UV} / \mathrm{H}_{2} \mathrm{O}_{2}$ /biosorbent technique, and our corona discharge system produced ozone, $\mathrm{H}_{2} \mathrm{O}_{2}$ and $\mathrm{OH}$ which are more efficient than the literature triple $\mathrm{UV} / \mathrm{H}_{2} \mathrm{O}_{2} /$ biosorbent system. 


\section{Conclusions}

The influence of different salts (such as $\mathrm{KCl}, \mathrm{NaCl}, \mathrm{CaCl}_{2}$ and $\mathrm{AlCl}_{3}$ ) on the dye degradation process in the presence of corona discharge was studied. The color removal behavior exploiting the high voltage pin-to-ground plate non-thermal plasma NTP system exhibited $82 \%$ dye removal at $11 \mathrm{~min}$. The total removal occurred at $28 \mathrm{~min}$. The presence of these salts in dye solutions will change the dye solution conductivity due to its role in changing the energy distribution through the dye solution and thus change the degradation efficiency of the dye. Decomposition efficiency increases with increasing solution conductivity. The increasing conductivity signals a reduction in color removal efficiency. The discharge energy and degradation efficiency are computed for diverse concentrations of $\mathrm{NaCl}, \mathrm{KCl}, \mathrm{CaCl}_{2}$ and $\mathrm{AlCl}_{3}$. It was detected that the presence of salts reduced the amount and the level of decolorization. The variation at the dye solution conductivity as the action of presence of salts will change the energy required for dye degradation (EE/O and energy yield) and all of these parameters were monitored. Moreover, the influence of the presence of $\mathrm{Cl}$ ions with cations in the different studied salts and its role in the dye degradation process was monitored. An investigation of the essential reactive species implicated in the oxidation of dye organic mixtures such as $\mathrm{O}_{3}$ in treated water and $\mathrm{H}_{2} \mathrm{O}_{2}$ was condicted. Generally, this work may prove helpful in the designing plasma systems appropriate for the treatment of industrial wastewaters in the presence of different salts.

Acknowledgments: The writers thankfully acknowledge STDF for supporting this investigation under the STDF project No. 10755.

Author Contributions: Ahmed El-Tayeb conceived, designed, and performed the experiments; analyzed the data; and wrote the manuscript. Ahmed H. El-Shazly and Marwa F. Elkady shared the analysis of the data and reviewed the manuscript.

Conflicts of Interest: The authors declare no conflict of interest.

\section{References}

1. Njatawidjaja, E.; Sugiarto, A.T.; Ohshima, T.; Sato, M. Decoloration of electrostatically atomized organic dye by the pulsed streamer corona discharge. J. Electrostat. 2005, 63, 353-359. [CrossRef]

2. Yang, Y.; Cho, Y.I.; Fridman, A. Plasma Discharge in Liquid Water Treatment and Applications; CRC Press: Boca Raton, FL, USA, 2012.

3. Mok, Y.S.; Jo, J.O.; Whitehead, J.C. Degradation of an azo dye Orange II using a gas phase dielectric barrier discharge reactor submerged in water. Chem. Eng. J. 2008, 142, 56-64. [CrossRef]

4. Dojcinovic, B.P.; Roglic, G.M.; Obradovic, B.M.; Kuraicac, M.M.; Kostićd, M.M.; Nešićb, J.; Manojlovićb, D.D. Decolorization of reactive textile dyes using water falling film dielectric barrier discharge. J. Hazard. Mater. 2011, 192, 763-771. [CrossRef] [PubMed]

5. El-Tayeb, A.; El-Shazly, A.H.; Elkady, M.F.; Abdel-Rahman, A. Decolorization of acid blue 25 dye by non-thermal plasma advanced oxidation process for industrial wastewater treatment. In Proceedings of the 15th IEEE International Conference on Environment and Electrical Engineering (EEEIC 2015), Rome, Italy, 10-13 June 2015.

6. PUBCHEM Open Chemistry Database. Available online: https://pubchem.ncbi.nlm.nih.gov/compound/ Acid_Blue_25\#section=InChI-Key (accessed on 28 July 2016).

7. El-Tayeb, A.; El-Shazly, A.H.; Elkady, M.F.; Abdel-Rahman, A. Simulation and Experimental Study for Degradation of Organic Dyes Using Dual pin-to-plate Corona Discharge Plasma reactors for Industrial Wastewater Treatment. Contrib. Plasma Phys. 2016, 56, 855-869. [CrossRef]

8. EL-Tayeb, A.; El Dein Adel, Z. Performance of Ceramic Insulator String for $132 \mathrm{kV}$ under Different Polluted Conditions. J. Energy Power Sources 2014, 1, 152-160.

9. El-Sayed Gouda, O.; El Dein Adel, Z.; EL-Tayeb, A. Prediction of flashover voltage and dry band location for polluted ceramic insulators using dynamic open-model. J. Energy Power Sources 2014, 1, 304-313.

10. El-Tayeb, A.; El-Shazly, A.H.; Elkady, M.F;; Abdel-Rahman, A. Investigation of the Decolorization Efficiency of Two Pin-to-Plate Corona Discharge Plasma System for Industrial Wastewater Treatment. Plasma Phys. Rep. 2016, 42, 887-899. [CrossRef] 
11. Cheng, H.H.; Chen, S.S.; Wu, Y.C.; Ho, D.L. Non-Thermal Plasma Technology for Degradation of Organic Compounds in Wastewater Control: A Critical Review. Environ. Eng. Manag. J. 2007, 17, 427-433.

12. El-Tayeb, A.; El-Shazly, A.H.; Elkady, M.F.; Abdel-Rahman, A. Non-thermal plasma as a new advanced technique for intensifying the industrial wastewater treatment. Desalination Water Treat. 2016, in press.

13. Wanga, H.; Lib, J.; Quana, X. Decoloration of azo dye by a multi-needle-to-plate high-voltage pulsed corona discharge system in water. J. Electrostat. 2006, 64, 416-421. [CrossRef]

14. El-Tayeb, A.; El-Shazly, A.H.; Elkady, M.F.; Abdel-Rahman, A. Simulation and experimental study for the effect of corona discharge plasma on the rate of wastewater treatment. Desalination Water Treat. 2016, in press.

15. Zhang, Y.; Zhou, M.; Lei, L. Degradation of 4-chlorophenol in different gas liquid electrical discharge reactors. Chem. Eng. J. 2007, 132, 325-333. [CrossRef]

16. El-Tayeb, A.; El-Shazly, A.H.; Elkady, M.F. Impacts of different salts on the degradation of acid blue 25 dye using non-thermal plasma. In Proceedings of the 16th IEEE International Conference on Environment and Electrical Engineering (EEEIC 2016), Florence, Italy, 7-10 June 2016.

17. Dojčinovića, B.P.; Roglićb, G.M.; Obradovićc, B.M.; Kuraicac, M.M.; Kostićd, M.M.; Nešićb, J.; Manojlović, D.D. Decolorization of reactive textile dyes using water falling film dielectric barrier discharge. J. Hazard. Mater. 2011, 192, 763-771. [CrossRef] [PubMed]

18. Overzet, L.J.; Leong-Rousey, F.Y. Time-resolved power and impedance measurements of pulsed radiofrequency discharges. Plasma Sources Sci. Technol. 1995, 4, 432443. [CrossRef]

19. Aleksandrov, N.L.; Kindysheva, S.V.; Kosarev, I.N. Plasma decay in air and $\mathrm{N}_{2}: \mathrm{O}_{2}: \mathrm{CO}_{2}$ mixtures at elevated gas temperatures. In Proceedings of the 47th AIAA Aerospace Sciences Meeting Including The New Horizons Forum and Aerospace Exposition, Orlando, FL, USA, 5-8 January 2009.

20. Šunka, P. Pulse electrical discharges in water and their applications. Phys. Plasmas 2001, 8, 25-87. [CrossRef]

21. Chang, J.; Lawless, P.; Yamamoto, T. Corona discharge processes. IEEE Trans. Plasma Sci. 1991, 19, $1152-1166$. [CrossRef]

22. Ono, R.; Oda, T. Ozone production process in pulsed positive dielectric barrier discharge. J. Phys. D Appl. Phys. 2007, 40, 176. [CrossRef]

23. Hayashi, Y.; Machmudah, S.; Takada, N.; Kanda, H.; Sasaki, K.; Goto, M. Decomposition of methyl orange using pulsed discharge plasm a at atmospheric pressure: Effect of different electrodes. Jpn. J. Appl. Phys. 2014, 53, 1. [CrossRef]

24. Lukes, P.; Locke, B.R. Degradation of Substituted Phenols in a Hybrid Gas-Liquid Electrical Discharge Reactor. Ind. Eng. Chem. Res. 2005, 44, 2921-2930. [CrossRef]

25. Krugly, E.; Martuzevicius, D.; Tichonovas, M.; Jankunaite, D.; Rumskaite, I.; Sedlina, J.; Racys, V.; Baltrusaitis, J. Decomposition of 2-naphthol in water using a non-thermal plasma reactor. Chem. Eng. J. 2015, 260, 188-198. [CrossRef]

26. Khan, H.; Ahmad, N.; Yasar, A.; Shahid, R. Advanced Oxidative Decolorization of Red Cl-5B: Effects of Dye Concentration, Process Optimization and Reaction Kinetics. Pol. J. Environ. Stud. 2010, 19, 83-92.

27. Marandi, R.; Olya, M.E.; Khosravi, M.; Khalilnezhad, R. Decolourisation of the dyes in aques solution using a new combinated system (UV/ $\mathrm{H}_{2} \mathrm{O}_{2}$ /biosorbent). J. Appl. Environ. Biol. Sci. 2013, 3, 71-80.

(C) 2016 by the authors; licensee MDPI, Basel, Switzerland. This article is an open access article distributed under the terms and conditions of the Creative Commons Attribution (CC-BY) license (http:/ / creativecommons.org/licenses/by/4.0/). 